NASA/TM-1999-208913

AIAA-99-0742

Study of Boundary Layer Development in a Two-Stage Low-Pressure Turbine

Daniel J. Dorney

Virginia Commonwealth University, Richmond, Virginia

David E. Ashpis

Lewis Research Center, Cleveland, Ohio

David E. Halstead and David C. Wisler

GE Aircraft Engines, Cincinnati, Ohio 
Since its founding, NASA has been dedicated to the advancement of aeronautics and space science. The NASA Scientific and Technical Information (STI) Program Office plays a key part in helping NASA maintain this important role.

The NASA STI Program Office is operated by Langley Research Center, the Lead Center for NASA's scientific and technical information. The NASA STI Program Office provides access to the NASA STI Database, the largest collection of aeronautical and space science STI in the world. The Program Office is also NASA's institutional mechanism for disseminating the results of its research and development activities. These results are published by NASA in the NASA STI Report Series, which includes the following report types:

- TECHNICAL PUBLICATION. Reports of completed research or a major significant phase of research that present the results of NASA programs and include extensive data or theoretical analysis. Includes compilations of significant scientific and technical data and information deemed to be of continuing reference value. NASA's counterpart of peerreviewed formal professional papers but has less stringent limitations on manuscript length and extent of graphic presentations.

- TECHNICAL MEMORANDUM. Scientific and technical findings that are preliminary or of specialized interest, e.g., quick release reports, working papers, and bibliographies that contain minimal annotation. Does not contain extensive analysis.

- CONTRACTOR REPORT. Scientific and technical findings by NASA-sponsored contractors and grantees.
- CONFERENCE PUBLICATION. Collected papers from scientific and technical conferences, symposia, seminars, or other meetings sponsored or cosponsored by NASA.

- SPECIAL PUBLICATION. Scientific, technical, or historical information from NASA programs, projects, and missions, often concerned with subjects having substantial public interest.

- TECHNICAL TRANSLATION. Englishlanguage translations of foreign scientific and technical material pertinent to NASA's mission.

Specialized services that complement the STI Program Office's diverse offerings include creating custom thesauri, building customized data bases, organizing and publishing research results ... even providing videos.

For more information about the NASA STI Program Office, see the following:

- Access the NASA STI Program Home Page at http://www.sti.nasa.gov

- E-mail your question via the Internet to help@sti.nasa.gov

- Fax your question to the NASA Access Help Desk at (301) 621-0134

- Telephone the NASA Access Help Desk at (301) 621-0390

- Write to: NASA Access Help Desk NASA Center for AeroSpace Information 7121 Standard Drive Hanover, MD 21076 
NASA/TM-1999-208913

AIAA-99-0742

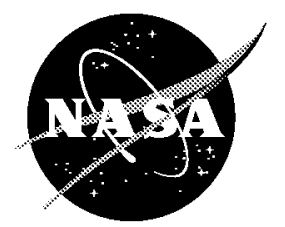

\section{Study of Boundary Layer Development in a Two-Stage Low-Pressure Turbine}

Daniel J. Dorney

Virginia Commonwealth University, Richmond, Virginia

David E. Ashpis

Lewis Research Center, Cleveland, Ohio

David E. Halstead and David C. Wisler

GE Aircraft Engines, Cincinnati, Ohio

Prepared for the

37th Aerospace Sciences Meeting \& Exhibit

sponsored by the American Institute of Aeronautics and Astronautics

Reno, Nevada, January 11-14, 1999

National Aeronautics and

Space Administration

Lewis Research Center 


\section{Acknowledgments}

The work of the first author was supported by NASA Lewis Research Center under Grant NCC3-645.

Trade names or manufacturers' names are used in this report for identification only. This usage does not constitute an official endorsement, either expressed or implied, by the National Aeronautics and Space Administration.

Available from

NASA Center for Aerospace Information 7121 Standard Drive

Hanover, MD 21076

Price Code: A03
National Technical Information Service 5285 Port Royal Road Springfield, VA 22100 Price Code: A03 


\section{STUDY OF BOUNDARY LAYER DEVELOPMENT IN A TWO-STAGE LOW-PRESSURE TURBINE}

\author{
Daniel J. Dorney * \\ Virginia Commonwealth University \\ Richmond, VA \\ David E. Halstead ${ }^{b}$ \\ GE Aircraft Engines \\ Cincinnati, $\mathrm{OH}$
}

\author{
David E. Ashpis ${ }^{a}$ \\ NASA Lewis Research Center \\ Cleveland, $\mathrm{OH}$ \\ David C. Wisler ${ }^{c}$ \\ GE Aircraft Engines \\ Cincinnati, $\mathrm{OH}$
}

\begin{abstract}
Experimental data from jet-engine tests have indicated that unsteady blade row interactions and separation can have a significant impact on the efficiency of low-pressure turbine stages. Measured turbine efficiencies at takeoff can be as much as two points higher than those at cruise conditions. Several recent studies have revealed that Reynolds number effects may contribute to the lower efficiencies at cruise conditions. In the current study numerical simulations have been performed to study the boundary layer development in a two-stage low-pressure turbine, and to evaluate the transition models available for low Reynolds number flows in turbomachinery. The results of the simulations have been compared with experimental data, including airfoil loadings and integral boundary layer quantities. The predicted unsteady results display similar trends to the experimental data, but significantly overestimate the amplitude of the unsteadiness. The time-averaged results show close agreement with the experimental data.
\end{abstract}

\section{NOMENCLATURE}

$C_{f} \quad$ Skin friction coefficient

$H$ Shape factor

$M \quad$ Mach number

$N \quad$ Nozzle/vane

$P \quad$ Pressure

\footnotetext{
*Associate Professor, Senior Member AIAA.

a Aerospace Engineer, Senior Member AIAA.

${ }^{b}$ Engineering Manager, Senior Member AIAA.

${ }^{c}$ Mgr of Univ. Strategic Alliances and Aero Tech Labs.
}

$\begin{array}{ll}P_{t} & \text { Total Pressure } \\ R e & \text { Reynolds number (axial chord, exit vel.) } \\ S & \text { Entropy, arc length } \\ S S L & \text { Normalized suction surface arc length } \\ T u & \text { Turbulence level } \\ u & \text { Local velocity } \\ U_{\infty} & \text { Free stream velocity } \\ \delta^{*} & \text { Displacement thickness/suction surface length } \\ \eta & \text { Efficiency } \\ \lambda & \text { Pressure gradient parameter } \\ \nu & \text { Kinematic viscosity } \\ \rho & \text { Density } \\ \sigma & \text { Intermittency function } \\ \theta & \text { Momentum thickness } \\ \Omega & \text { Rotational velocity }\end{array}$

\section{SUBSCRIPTS}

$\begin{array}{ll}t t & \text { Total-to-total quantity } \\ \text { wet } & \text { Wetted distance } \\ \theta & \text { Momentum thickness } \\ 1 & \text { First nozzle inlet } \\ 2 & \text { First nozzle exit/first rotor inlet } \\ 3 & \text { First rotor exit/second nozzle inlet } \\ 4 & \text { Second nozzle exit/second rotor inlet } \\ 5 & \text { Second rotor exit }\end{array}$

\section{INTRODUCTION}

Experimental data from jet-engine tests have indicated that unsteady blade row (wake) interactions and separation can have a significant impact on the efficiency of turbine stages. The effects of these interactions can be intensified in low-pressure turbine stages because of the low Reynolds number operating environment. Measured turbine efficiencies at takeoff can be as much as two points higher than those at cruise conditions [1]. Thus, during the last decade a 
significant amount of effort has been put into determining the effects of transition and turbulence on the performance of low pressure turbine stages. Experimental investigations have been performed, for example, by Hodson et al. [2, 3, 4, 5], Halstead et al. [6, 7], Qiu et al. [8], Sohn et al. [9] and Boyle et al. [10]. These investigations have helped identify/clarify the roles that factors such as the Reynolds number, free stream turbulence intensity, pressure gradient and curvature have in the generation of losses. In particular, it has been determined that [1]:

- At low to moderate Reynolds numbers there is a laminar region extending some distance from the leading edge.

- The boundary layer may separate, particularly on the suction surface of the blade. Separation may occur in the form of a closed bubble, or as massive separation with no reattachment (resulting in large losses). The pressure surface may have cove separation, and small separation bubbles may exist near the leading edge. The separation bubbles often originate in transitional flow, while reattachment is usually in turbulent flow.

- The interaction of incoming wakes with the boundary layer often creates a convected transitional or turbulent patch, which is trailed by a "calmed" region. The calmed region is a relaxation region between the patch and the laminar boundary layer.

In parallel to the experimental investigations, there have been significant analytical efforts to improve the modeling of transition. Examples of such efforts include the works of Mayle [11], Reshotko [12] and Gostelow et al. [13, 14]. These newer models show promise of providing accurate transition predictions over a wide rangle of flow conditions [15], although they have yet to be implemented into the numerical flow analyses used by the turbine design community. Some recent computational investigations of interest include the works of Chernobrovkin and Lakshminarayana [16], Kang and Lakshminarayana [17], Huang and Xiong [18] and Eulitz and Engel [19].

The focus of the current effort has been to use a viscous, unsteady quasi-three-dimensional NavierStokes analysis to study boundary layer development in a two-stage low-pressure turbine. A two-layer algebraic turbulence model, along with two natural transition models and a bubble transition model, have been evaluated at both take-off and cruise operating conditions. The geometry used in the simulations has been the subject of extensive experiments $[6,7]$. The predicted results have been compared with experimental data, including airfoil loadings and integral boundary layer quantities.

\section{ALGORITHM}

The current work is based on an extension of an approach developed by Rai [20]. The approach is reviewed in brief here. The flow field is divided into two types of zones. O-type grids are used to resolve the flow field near the airfoils. The O-grids are overlaid on H-grids which are used to resolve the flow field in the passages between airfoils. The $\mathrm{H}_{-}$ grids are allowed to slip relative to one another to simulate the relative motion between rotors and stators. The thin-layer or full Navier-Stokes equations are solved on both the $\mathrm{O}$ - and $\mathrm{H}$-grids. The governing equations are cast in the strong conservation form. A fully implicit, finite-difference method is used to advance the solution of the governing equations in time. A Newton-Raphson subiteration scheme is used to reduce the linearization and factorization errors at each time step. The convective terms are evaluated using a third-order-accurate upwind-biased Roe scheme. The viscous terms are evaluated using second-order accurate central differences and the scheme is second-order accurate in time. Details of the solution procedure and boundary conditions are discussed in Ref. [21]

\section{TURBULENCE MODEL}

The two-layer algebraic model based on the work of Baldwin and Lomax (BL) was used to model turbulence [22]. Several modifications were made to the original BL model based on previous experiences with compressor and turbine geometries:

- The switchover location between the inner and outer models cannot move more than a specified number of grid points between adjacent streamwise locations. This eliminates non-physical gradients in the turbulent viscosity near separation points.

- A second derivative smoothing function is used on the turbulent viscosity field in separated flow regions. This also helps remove non-physical gradients in the turbulent viscosity in separation regions.

- A cutoff value is imposed on the turbulent viscosity (nominally 1200 times the free stream laminar viscosity).

The comparison of predicted and experimental integral boundary layer quantities warrants discussion 
of the technique used to determine the location of the boundary layer edge in the simulations. The following steps, based on the work of Davis et al. [23], were used to determine the edge of the boundary layer:

1. determine the minimum value of $\left|U_{\infty}-u\right|$, where $U_{\infty}$ is based on isentropic conditions

2. correct the location based on where the local vorticity exceeds a specified limiting value

3. within the new range, determine where $u$ is greater than $U_{\infty}$

\section{TRANSITION MODELS}

The low Reynolds number environment in lowpressure turbines suggests that the flow may be transitional. Two natural transition models have been utilized in the analysis: the Abu-Ghannam and Shaw (ABS) model [24] and the Mayle model [11].

\section{ABS Model}

The ABS model determines the start of transition based on the momentum thickness Reynolds number

$$
R e_{\theta}=163+\exp \left[F\left(\lambda_{\theta}\right)-\frac{F\left(\lambda_{\theta}\right)}{6.91} T u\right]
$$

where

$$
\begin{aligned}
F\left(\lambda_{\theta}\right) & \left.=6.91+12.75 \lambda_{\theta}+63.64\left(\lambda_{\theta}\right)^{2} \quad \lambda_{\theta}<02\right) \\
F\left(\lambda_{\theta}\right) & =6.91+2.48 \lambda_{\theta}-12.27\left(\lambda_{\theta}\right)^{2} \quad \lambda_{\theta}>0(3) \\
\lambda_{\theta} & =\frac{\theta^{2}}{\nu} \frac{d U_{\infty}}{d S}
\end{aligned}
$$

This model is considered valid up to turbulence levels of $T u=10 \%$. The end of the transition region is calculated as

$$
R e_{L}=31.8\left(R e_{\theta}\right)^{1.6}
$$

In the region between the start and end of transition the intermittency function, $\sigma$, is determined using the model developed by Dhawan and Narasimha [25],

$$
\sigma=1-\exp \left(-4.64 \xi^{2}\right)
$$

Note, the intermittency function, which has a value of $\sigma=0$ for laminar flow and $\sigma=1$ for turbulent flow, is multiplied by value of the viscosity calculated in the turbulence model. The current implementation of the ABS model has been tested on both compressor and turbine geometries $[26,27]$.

\section{Mayle Model}

The Mayle model also bases the start of transition on the momentum thickness Reynolds number, where

$$
R e_{\theta}=400 T u e^{-5 / 8}
$$

The intermittency function model is the same as outlined above for the ABS model. Note that in both the ABS and Mayle transition models the local turbulence quantities (e.g., the value of $T u$ ) are used to calculate the start of transition.

\section{Roberts' Model}

For cases involving separation bubbles the model developed by Roberts [28], and modified by Davis et al. [29], is used:

$$
R e_{\theta}=25000 \log _{10}(1 / \tanh (0.173205 T u))
$$

Instantaneous transition is assumed using the bubble model.

\section{GEOMETRY AND GRID}

The test article used in this study has been studied extensively by Halstead et al. [6, 7]. The turbine is typical of the those found in modern aircraft engines (see Fig. 1). The turbine design parameters are shown in Table 1.

The experimental turbine contains 82 first-stage nozzles, 72 first-stage rotors, 108 second-stage nozzles and 72 second-stage stators (i.e., a 82-72-108-72 blade count ratio). For modeling purposes a blade count ratio of 78-78-104-78 was assumed; thus requiring the use of 3 first-stage nozzles, 3 first-stage rotors, 4 second-stage nozzles and 3 second-stage rotors in the simulations. The airfoils in each blade row were scaled to keep the pitch-to-chord ratio the same as in the experiments. The O-grids for each blade row contained contained $251 \times 51$ (streamwise $\times$ tangential) grid points. The H-grids in the first-stage nozzle passage each contained $108 \times 96$ grid points, the $H$-grids in the first-stage rotor passage each contained $125 \times 96$ grid points, the H-grids in the second-stage nozzle passage each contained $120 \times 96$ grid points and the $\mathrm{H}$-grids in the second-stage rotor passage each contained $175 \times 96$ grid points. Thus, the complete grid topology contained 329,997 grid points (see Fig. 2, which shows every fourth point). The average value of $y^{+}$, the non-dimensional distance of the first grid point above the surface, was approximately 1.0 for all four blade rows. The dimensions of the O-grid were arrived at based on the value of $y^{+}$and the number 
of points within the boundary layer, while the dimensions of the H-grid were determined by performing wake convection simulations in the absence of airfoils.

The simulations were run on Silicon Graphics Inc. (SGI) Origin 200 workstations with $195-\mathrm{MHz}$ processors. The average computation time was $4 \times 10^{-5}$ sec/grid point/iteration. Each simulation was run for 20 global periods, at 18,000 time steps per global period. A global period is defined as the second rotor moving through a distance equal to 4 second nozzle pitches or, similarly, the first rotor moving through a distance equal to 3 first nozzle pitches. The 20 global periods allowed the efficiency, losses and integral boundary layer quantities to become time periodic.

\section{RESULTS}

Two different operating points have been studied: one at takeoff conditions (Point 5A) and one at cruise conditions (Point 5D). The parameters associated with the two test conditions are outlined in Table 2. In accordance with the experiments, the free stream turbulence level (used in the transition models) was set at $T u=3 \%$.

\section{Point 5A}

Entropy contours are useful for tracking the convection of airfoil wakes. Figure 3 illustrates instantaneous entropy contours in the turbine. For comparison, a sketch of experimental wake convection is shown in Fig. 4 [7]. In both Figs. 3 and 4 the stretching of the wakes from the pressure side of an airfoil to the suction side of the adjacent airfoil is clearly visible. At takeoff conditions there is little flow separation, as will be supported by the presentation of skin friction envelopes.

Numerical and experimental time-averaged loadings on the second nozzle and second rotor are shown in Figs. 5 and 6, respectively. The predicted results exhibit good agreement with the experimental data, except in the suction surface leading edge region of the second nozzle. The differences in this region suggest the flow entering the second nozzle in the simulations has somewhat greater positive incidence. On the second rotor, both the numerical results and experimental data show an acceleration region near the suction surface leading edge followed by a zone of constant velocity, a second acceleration region and finally a deceleration zone as the flow moves downstream of the throat into the uncovered portion of the passage.

Figure 7 contain time histories (over 3 wake passing periods) of the transition locations on two adjacent second-stage nozzles using the ABS transition model.
The numerical data is plotted at a density of 33 points per wake passing period; thus, the curves represent information from every 180 th time step. In the region between the passing wakes the (average) predicted start of transition is approximately $67 \%$ of the suction surface length on one nozzle and $57 \%$ on the adjacent nozzle, as compared to the experimentally observed value of $52 \%$ [7]. In the presence of the passing rotor wakes, the prediced start of transition is at $36 \%$ of the suction surface length on one nozzle and $21 \%$ on the adjacent nozzle, as compared to $32 \%$ in the experiments. The differences in the predicted location of transition onset for the two adjacent nozzles may due to clocking effects induced by the $3-3-4-3$ blade count ratio. The different nozzle counts in the first and second stages cause the time-averaged location of the first-stage nozzle wakes in the second-stage nozzle passages to vary around the annulus of the machine. Similar behavior was observed in the experimental study of Ref. [7]. The time-averaged location at the end of transition is about $95 \%$ of the suction surface length on both nozzles interrogated, compared to experimental values of $80 \%$ in the wake-induced transition region and $73 \%$ in the transition region between wakes [7]. Thus, the transition model adequately predicts the onset of transition in the presence of the rotor wakes, but predicts the beginning of transition about $10 \%$ too far downstream between the rotor wakes. The end of transition is consistently predicted further downstream than indicated by the experimental data.

A space-time diagram of the predicted shape factor (over 3 wake passing periods) on the suction surface of a second-stage nozzle (the adjacent nozzle from above) is shown in Fig. 8. For comparison purposes, the space-time diagram from an unsteady boundary layer code (discussed in Ref. [30]) is presented in Fig. 9. Both figures show a large region of laminar flow downstream of the leading edge. The current results (see Fig. 8) indicate larger periodic variations than were observed in the unsteady boundary layer calculation. The predicted transition length in the wake-induced transition region (denoted by 1 in Fig. 9) is approximately $74 \%$ of the suction surface length, as compared to $17 \%$ in the unsteady boundary layer calculation and $48 \%$ in the experiment [30]. In the region between rotor wakes (denoted by 3 in Fig. 9) the current analysis, as well as the unsteady boundary layer analysis and experimental data of Ref. [7, 30], indicate that the start of transition moves as far downstream as $90 \%$ of the suction surface length.

Figures 10 thru 17 contain time histories of the displacement thickness and shape factor at 50\%, 68\%, 
$82 \%$ and $94 \%$ of the suction surface length on the second nozzle. Included in these figures are the predicted results using both the ABS and Mayle transition models, as well as the experimental data. At $50 \%$ of the suction surface length the predicted displacement thickness distributions show good agreement with the experimental data (see Fig. 10). The predicted shape factors exhibit much larger temporal variations than were recorded in the experiments (see Fig. 11). Similar large-amplitude variations were observed in the unsteady boundary layer code calculations of Ref. [30]. At the 50\% location both the ABS and Mayle models produce similar displacement thickness traces, but the Mayle model produces much larger values of the shape factor in the time period just before the passing of rotor wakes (i.e., path $W$, using the nomenclature of Refs. [6, 7, 30]). This is caused by the Mayle model producing smaller values of the momentum thickness during this time period. Moving downstream to the $68 \%, 82 \%$ and $94 \%$ surface length locations the following trends are observed:

- In the region between rotor wakes (paths $\mathrm{X}$ and $\mathrm{Y}$ ), the predicted displacement thickness traces show fair to good agreement with the experimental data. At $68 \%$ and $82 \%$ of the suction surface length (see Figs. 12 and 14) the Mayle model shows closer agreement with the experimental data than the ABS model in the region between rotor wakes.

- The predicted displacement thickness distributions show large amplitude variations in the rotor wake (path W), much larger than the variations indicated by the experimental data.

- The predicted temporal variations in the shape factor are much larger than indicated by the experimental data. In particular, the Mayle model produces much larger fluctuations throughout the wake passing period. The ABS model shows somewhat closer agreement in the region between wakes, but still generates shape factor fluctuations which are significantly greater than the experimental data.

As a point of reference, displacement thickness and shape factor histories from a fully turbulent solution were also investigated. The amplitude of the shape factor fluctuations were greater in the turbulent simulation than in the ABS transitional simulation.

Minimum, maximum and time-averaged distributions of the displacement thickness on the suction surface of the second nozzle are shown in Fig. 18, while the corresponding time-averaged shape factor distributions are shown in Fig. 19. Although the predicted time-histories in Figs. 10-17 show much larger temporal variations than the experimental data indicate, the time-averaged values obtained with the ABS model show excellent agreement with the experimental data. The displacement thickness distribution obtained with the Mayle model shows very good agreement with the experimental data, but the shape factor is significantly overpredicted.

Considering the facts that: 1) the simulations overpredict the amplitude of the displacement thickness and shape factor fluctuations, and 2) the timeaveraged results show close agreement with the experimental data, it is reasonable to assume that the modeled blade count ratio may be affecting the unsteady results. While a $3-3-4-3$ blade count ratio is a reasonable approximation to the actual blade count ratio, the equal number of airfoils in the first nozzle and rotor rows probably causes an overprediction of the potential interaction.

Skin friction envelopes for each of the four blade rows are given in Figs. 20-23, respectively. There is little unsteadiness in the skin friction distribution on the pressure surface of the first nozzle (see Fig. 20). The suction surface of the first nozzle exhibits unsteadiness downstream of the throat. In addition, the flow approaches separation near $75 \%$ of the suction surface length. The pressure surface of the first rotor experiences intermittent separation in the cove region, although the flow remain attached in a timeaveraged sense (see Fig. 21). There is a considerable amount of unsteadiness generated on the suction surface of the first rotor; the unsteadiness is a result of: 1) the passing wakes from the first nozzle, 2) potential interaction with the first and second nozzles, and 3 ) the time-varying transition process. The cove regions on both the second nozzle and rotor airfoils undergo intermittent flow separation, and approach separation in a time-averaged sense (see Figs. 22 and $23)$. The suction surface of the second nozzle and rotor airfoils show a large amount of unsteadiness, which correlates closely to the transition regions.

While a considerable amount of effort has been given to studying the process of transition in low pressure turbines, it is suggested (based on the skin friction data) that the cove region of the pressure surface may warrant further investigation.

\section{$\underline{\text { Point 5D }}$}

Figure 24 illustrates instantaneous entropy contours in the turbine. The wake convection is somewhat similar to that illustrated in Fig. 3, except that the airfoils generate much stronger/distinct vortex 
streets at the lower Reynolds number. This phenomena acts to increase the high-frequency content of the unsteady flow.

Figure 25 contains a time history (over 3 wake passing periods) of the transition locations on two adjacent second-stage nozzles using the ABS transition model. The numerical data is again plotted at a density of 33 points per wake passing period. In the region between the rotor wake passings the predicted start of transition is $80 \%$ of the suction surface length on one nozzle and approximately $85 \%$ on the adjacent nozzle, compared to the experimentally observed value of $76 \%$. In the presence of the passing rotor wakes, the prediced onset of transition is at $56 \%$ of the suction surface length on one nozzle and at an average of $52 \%$ on the adjacent nozzle, as compared to $71 \%$ in the experiments. Thus, the predicted results indicate the onset of transition too far downstream between the wakes and too far upstream in the region of the passing rotor wakes. In addition, in the region between rotor wakes bubble transition tends to occur, while attached-flow natural transition is predominant in the presence of passing rotor wakes. In the simulations the end of transition varied between $86 \%$ of the suction surface length (instantaneous bubble transition in between rotor wakes) and the trailing edge (attached-flow natural transition in the rotor wakes), while the experimental data indicate the end of transition at the trailing edge throughout the wake passing period.

A space-time diagram of the predicted shape factor (over 3 wake passing periods) is shown in Fig. 26. Compared with Fig. 8, the results for the lower Reynolds number indicate the regions of laminar flow extending much closer to the trailing edge.

Figures 27 thru 34 contain time histories of the displacement thickness and shape factor at 50\%, 68\%, $82 \%$ and $94 \%$ of the suction surface length on the second nozzle. Included in these figures are the predicted results using both the ABS and Mayle transition models, as well as the experimental data. At $50 \%$ of the suction surface length the predicted displacement thickness shows good agreement with the experimental data outside of the region of the rotor wakes (denoted by paths $\mathrm{Z}, \mathrm{X}$ and $\mathrm{Y}$ in Fig. 27). In the region of the passing rotor wakes (denoted by path $W$ ), however, the predicted results indicate a decrease in the displacement thickness while the experimental data indicate that the displacement thickness increases slightly. The behavior of the predicted results in the region of the passing rotor wakes also contrasts with the predicted results for operating Point 5A (see Fig. 10). The predicted shape factor exhibits fair agreement with the experimental data just be- fore and as the rotor wakes pass, but shows a rapid decrease in the shape factor as the rotor wakes pass which is not substantiated by the experimental data (see Fig. 28). Moving downstream to the 68\%, 82\% and $94 \%$ length locations the following trends are observed:

- The predicted results show large amplitude unsteadiness at twice the wake passing frequency, significantly more than was observed at the takeoff Reynolds number. The increased high-frequency unsteadiness in the boundary layer quantities correlates with increased highfrequency unsteadiness in the pressure field. Figures 37 and 38 contain Fourier decompositions of the unsteady pressure at $96 \%$ of the suction surface length for operating conditions $5 \mathrm{~A}$ and $5 \mathrm{D}$, respectively. There is significantly more highfrequency unsteadiness in the pressure at the lower Reynolds number. Some of the unsteadiness may be due to nozzle clocking effects as discussed in Ref. [7]. A portion of the increased unsteadiness may also be due to the enhanced vortex shedding shown in Fig. 24.

- The experimental data displays an increasingly large amount of unsteadiness at twice the wake passing frequency, although the amplitude is smaller than predicted by the simulations.

- The ABS and Mayle models produce similar results at $50 \%$ and $68 \%$ of the suction surface length, but start to show discrepancies further along the surface.

- Both the predicted results and experimental data indicate increased displacement thickness and decreased shape factor in the presence of the rotor wakes (path W).

- At $50 \%, 68 \%$ and $82 \%$ of the suction surface length both the predictions and data show a gradual decrease of the displacement thickness in the region between rotor wakes (paths $\mathrm{X}, \mathrm{Y}$ and Z).

Time-averaged distributions of the displacement thickness and shape factor on the suction surface of the second nozzle are shown in Figs. 35 and 36, respectively. Similar to the results at the higher Reynolds number, the predicted results show good agreement with the experimental data. While the two transition models produce similar results over the majority of the surface, the Mayle model produces a small increase in the displacement thickness and a large increase in the shape factor near the location of time-averaged transition. 
Skin friction envelopes for each of the four blade rows are given in Figs. 39-42, respectively. In general, the skin friction distributions exhibit more unsteadiness than at the higher Reynolds number (see Figs. 20-23). Similar to the results presented in Figs. 20-23, the cove region on the pressure surface of all the airfoils, except for the first nozzle, experience intermittent separation. In contrast to the results for Point 5A, the suction surfaces of the airfoils in the first three blade rows show intermittent flow separation from approximately $75 \%$ of the surface length to the trailing edge.

\section{CONCLUSIONS}

A series of numerical simulations have been performed for flow through a two-stage low-pressure turbine. The simulations were performed for two different operating conditions (takeoff and cruise), using two different natural transition models and one bubble transition model. The results of this study have shown that:

- the Abu-Ghannam/Shaw and Mayle transition models both yield accurate results for the time-averaged displacement thickness and shape factor distributions, although the AbuGhannam/Shaw results shows closer agreement with the experimental data

- the predicted displacement thickness histories show similar trends to the experimental data in the region between rotor wakes, but display much larger variations than the experimental data in the region of the rotor wakes

- the predicted shape factor histories show more unsteadiness than the experimental data; both the predicted results and experimental data show significant unsteadiness at twice the bladepassing frequency near the trailing edge of the second nozzle

- the predicted transition location histories for adjacent second-stage nozzles suggest that airfoil clocking plays a prominent role in the transition process

- the simulations indicate increased unsteadiness (e.g., pressure field and enhanced vortex shedding) at the cruise operating conditions

- intermittent cove separation on the pressure surface of the airfoils occurs at both the takeoff and cruise conditions
- the suction surface of the airfoils intermittently separate at the low Reynolds number (cruise) conditions, but not at the high Reynolds number (takeoff) conditions

Future simulations will focus on quantifying the effects of nozzle and/or rotor clocking on the boundary layer development in the turbine.

\section{ACKNOWLEDGEMENT}

The work of the first author was supported by NASA Lewis Research Center under Grant NCC3645.

\section{References}

[1] Simon, F. F. and Ashpis, D. E., "Progress in Modeling of Laminar to Turbulent Transition on Turbine Vanes and Blades," International Conference on Turbulent Heat Transfer, 1996, also NASA TM 107180.

[2] Hodson, H. P., "The Development of Unsteady Boundary Layers on the Rotor of an Axial Flow Turbine," AGARD CP-351, 1983.

[3] Hodson, H. P., "Measurements of WakeGenerated Unsteadiness in the Rotor Passages of Axial Flow Turbines," ASME Paper 84-GT$189,1984$.

[4] Hodson, H. P., "Boundary Layer Transition and Separation Near the Leading Edge of a HighSpeed Turbine Blade," Journal of Engineering for Gas Turbines and Power, Vol. 107, 1985, pp. 127-134.

[5] Hodson, H. P., Huntsman, I. and Steele, A. B., "An Investigation of Boundary Layer Development in a Multistage LP Turbine," Journal of Turbomachinery, Vol. 116, 1994, pp. 375-383.

[6] Halstead, D. E., Wisler, D. C., Okiishi, T. H., Walker, G. J., Hodson, H. P. and Shin, H.-W., "Boundary Layer Development in Axial Compressors and Turbines - Part 1 of 4: Composite Picture," ASME Paper 95-GT-461, Houston, TX, 1995, also published in the ASME Journal of Turbomachinery.

[7] Halstead, D. E., Wisler, D. C., Okiishi, T. H., Walker, G. J., Hodson, H. P. and Shin, H.-W., "Boundary Layer Development in Axial Compressors and Turbines - Part 3 of 4: LP Turbines," ASME Paper 95-GT-463, Houston, TX, 1995, also published in the ASME Journal of Turbomachinery. 
[8] Qiu, S. and Simon, T. W., "An Experimental Investigation of Transition as Applied to Low Pressure Turbine Suction Surface Flows," ASME Paper 97-GT-455, Orlando, Fl.

[9] Sohn, K. H., Shyne, R. J. and Dewitt, K. J., "Experimental Investigation of Boundary Layer Behavior in a Simulated Low Pressure Turbine," ASME Paper 98-GT-34, International Gas Turbine and Aeroengine Congress and Exhibition, Stockholm, Sweden, June 2-5, 1998.

[10] Boyle, R. J., Lucci, B. L., Verhoff, V. G., Camperchioli, W. P. and La, H., "Aerodynamics of a Transitioning Turbine Stator Over a Range of Reynolds Numbers," 98-GT-285, International Gas Turbine and Aeroengine Congress and Exhibition, Stockholm, Sweden, June 2-5, 1998 .

[11] Mayle, R. E., "The Role of Laminar-Turbulent Transition in Gas Turbine Engines," ASME Paper 91-GT-261, Orlando, FL, 1991.

[12] Reshotko, E., "Boundary Layer Instability, Transition and Control," AIAA Paper 94-0001, Reno, NV, 1994.

[13] Gostelow, J. P., Blunder, A. R. and Walker, G. J., "Effects of Free-Stream Turbulence and Adverse Pressure Gradients on Boundary Layer Transition," ASME Journal of Turbomachinery, Vol. 116, 1994, pp. 392-404.

[14] Gostelow, J. P., Melwani, N. and Walker, G. J., "Effects of Streamwise Pressure Gradient on Turbulent Spot Development, ASME Paper 95GT-303, Houston, TX, 1995.

[15] Boyle, R. J. and Simon, F. F., "Mach Number Effects on Turbine Blade Transition Length Prediction," ASME Paper 98-GT-367, International Gas Turbine and Aeroengine Congress and Exhibition, Stockholm, Sweden, June 2-5, 1998, also accepted for publication in the ASME Journal of Turbomachinery.

[16] Chernobrovkin, A. and Lakshminarayana, B., "Development and Validation of Navier-Stokes Procedure for Turbomachinery Unsteady Flow," AIAA Paper 97-3281, Seattle, WA, 1997.

[17] Kang, D. J. and Lakshminarayana, B., "Numerical Prediction of Unsteady Transitional Flow Due to Rotor Stator Interaction," AIAA Paper 97-2752, Seattle, WA, 1997.
[18] Huang, P. G. and Xiong, G., "Transition and Turbulence Modeling of Low Pressure Turbine Flows," AIAA Paper 98-0339, Reno, NV, 1998.

[19] Eulitz, F. and Engel, K., "Numerical Investigation of Wake Interaction in a Low Pressure Turbine," ASME Paper 98-GT-563, International Gas Turbine and Aeroengine Congress and Exhibition, Stockholm, Sweden, June 2-5, 1998.

[20] Rai, M. M., "Navier-Stokes Simulations of Rotor/Stator Interactions Using Patched and Overlaid Grids," AIAA Journal of Propulsion and Power, Vol. 3, No. 5, Sept., 1987, pp.387-396.

[21] Dorney, D. J., and Verdon, J. M., "Numerical Simulations of Unsteady Cascade Flow," ASME Journal of Turbomachinery, Vol. 116, No. 4, October, 1994, pp. 665-675.

[22] Baldwin, B. S., and Lomax, H., "Thin Layer Approximation and Algebraic Model for Separated Turbulent Flow", AIAA Paper 78-257, Huntsville, AL, January, 1978.

[23] Davis, R. L., Hobbs, D. E., and Weingold, H. D., "Prediction of Compressor Cascade Performance Using a Navier-Stokes Technique," ASME Journal of Turbomachinery, Vol. 110, No. 4, October, 1988 , pp. 520-531.

[24] Abu-Ghannam, B. J., and Shaw, R., "Natural Transition of Boundary Layers - The Effects of Turbulence, Pressure Gradient, and Flow History," IMechE Journal of Mechanical Engineering Science, Vol. 22, No. 5, 1980, pp. 213-228.

[25] Dhawan, S., and Narasimha, R., "Some Properties of Boundary Layer Flow During Transition from Laminar to Turbulent Motion," Journal of Fluid Mechanics, Vol. 3., 1958.

[26] Dorney, D. J., "A Comparative Study of Four Algebraic Transition Models," SAE Journal of Aerospace, Vol. 103, Section 1, 1994, pp. 112119.

[27] Dorney, D. J., and Ashpis, D., "Study of Low Reynolds Number Effects on the Losses in LowPressure Turbine Blade Rows," AIAA 98-3575, 34th AIAA/ASME/SAE/ASEE Joint Propulsion Conference, Cleveland, OH, July 13-15, 1998, also to appear in the International Journal of Turbo and Jet Engines.

[28] Roberts, W. B., "Calculation of Laminar Separation Bubbles and Their Effect on Airfoil Performance," AIAA Paper 79-0285, New Orleans, LA, January, 1979. 
[29] Davis, R. L., Carter, J. E., and Reshotko, E., "Analysis of Transitional Separation Bubbles on Infinite Swept Wings," AIAA Journal, Vol. 25, No. 3, March, 1987, pp. 421-428.

[30] Halstead, D. E., Wisler, D. C., Okiishi, T. H., Walker, G. J., Hodson, H. P. and Shin, H.-W., "Boundary Layer Development in Axial Compressors and Turbines - Part 4 of 4: Computations and Analyses," ASME Paper 95-GT-463, Houston, TX, 1995, also published in the ASME Journal of Turbomachinery.

\begin{tabular}{|l|c|c|c|}
\hline Quantity & N1 & N2 & Rotor \\
\hline Solidity & 1.64 & 1.68 & 1.48 \\
Aspect Ratio & 3.97 & 5.10 & 3.87 \\
Chord, mm & 76.2 & 59.7 & 78.7 \\
Stagger, deg from axial & 39.8 & 22.9 & 34.9 \\
Camber, deg & 60.0 & 102.4 & 96.9 \\
No. of airfoils & 82 & 108 & 82 \\
Axial gap, mm & 25.4 & 25.4 & - \\
\hline
\end{tabular}

Table 1: Turbine design parameters.

\begin{tabular}{|l|c|c|}
\hline & \multicolumn{2}{|c|}{ Test Point } \\
\hline Quantity & $5 \mathrm{~A}$ & $5 \mathrm{D}$ \\
$T_{t 1}\left({ }^{\circ} \mathrm{K}\right)$ & 287.8 & 287.8 \\
$P_{t 1}\left(N / m^{2}\right)$ & 97,642 & 100,839 \\
$P_{1}\left(N / m^{2}\right)$ & 96,514 & 100,716 \\
$\alpha_{1}$, deg from axial & 0.0 & 0.0 \\
$\Omega(R P M)$ & 599.7 & 185.1 \\
$M_{1}$ & 0.1289 & 0.0417 \\
$P_{5} / P_{t 1}$ & 0.8614 & 0.8614 \\
\hline
\end{tabular}

Table 2: Turbine design parameters. 


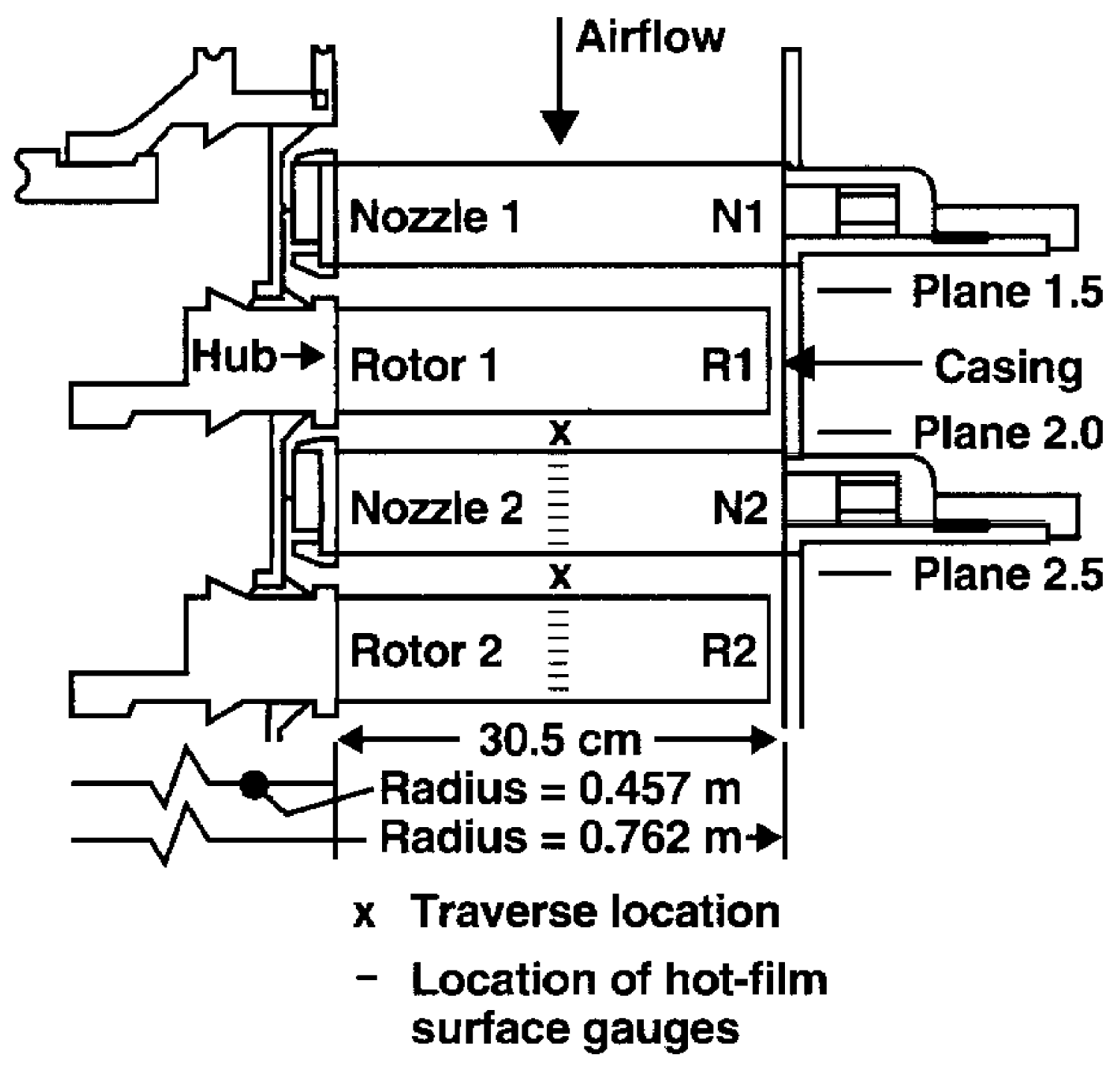

Figure 1: Two-stage low-pressure turbine. 


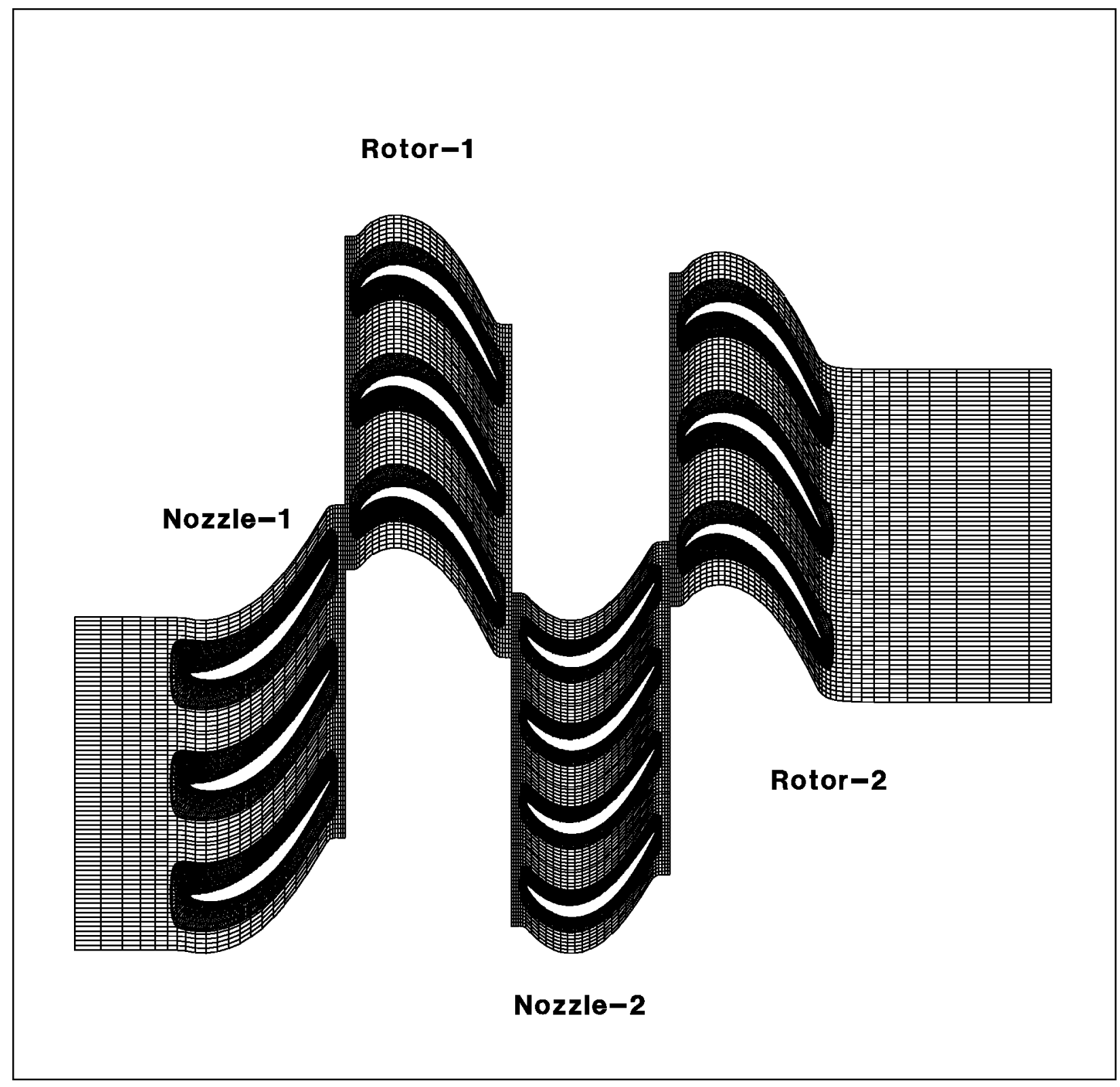

Figure 2: Two-stage low-pressure turbine. 


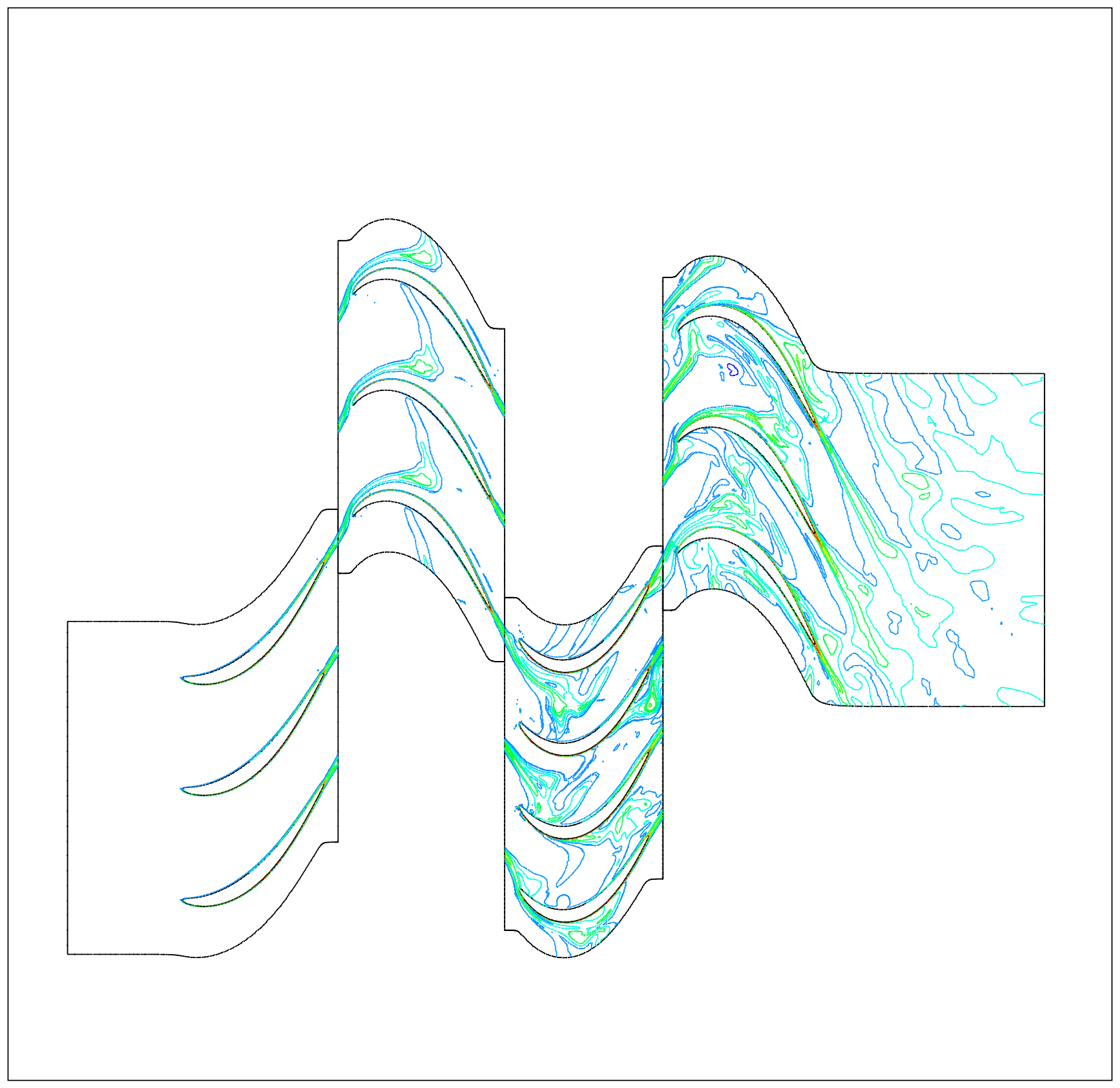

Figure 3: Instantaneous entropy contours, Point 5a, ABS. 


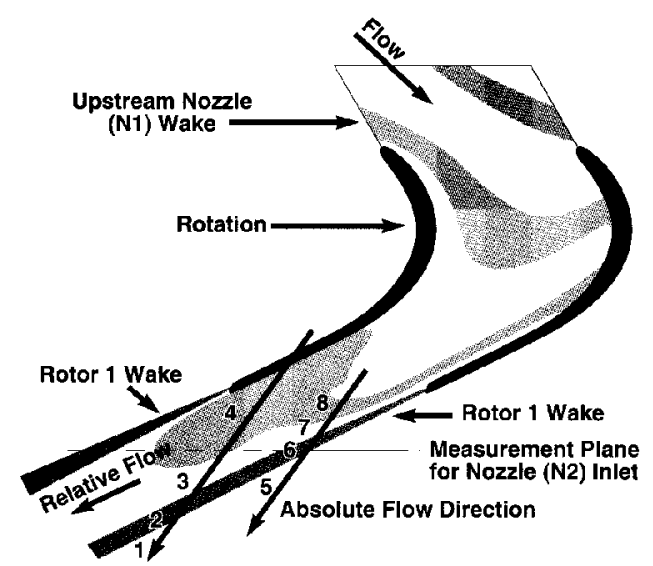

Figure 4: Sketch of experimental wake convection.

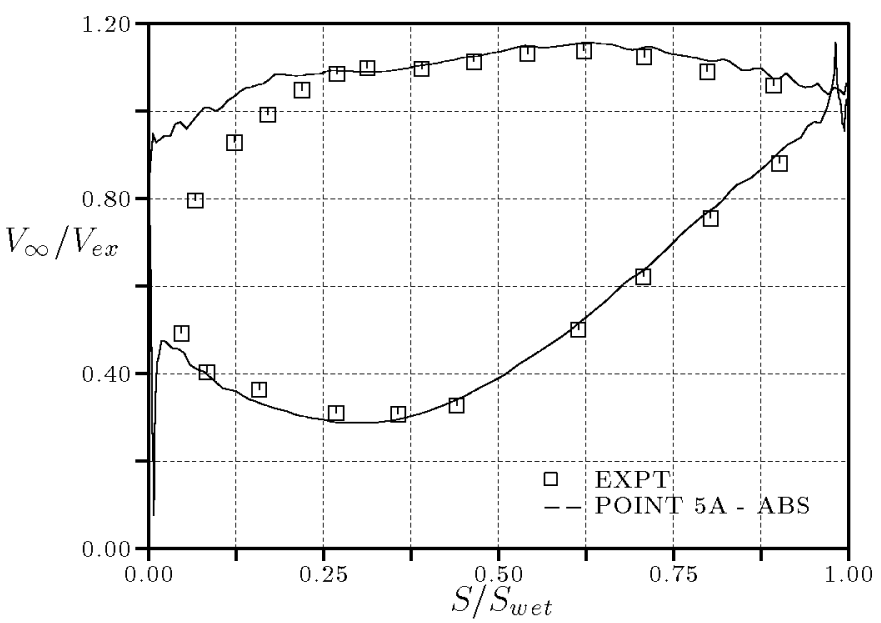

Figure 5: Normalized loading on nozzle-2, Point 5A, Figure 7: Transition location history, Point 5A, ABS. ABS .

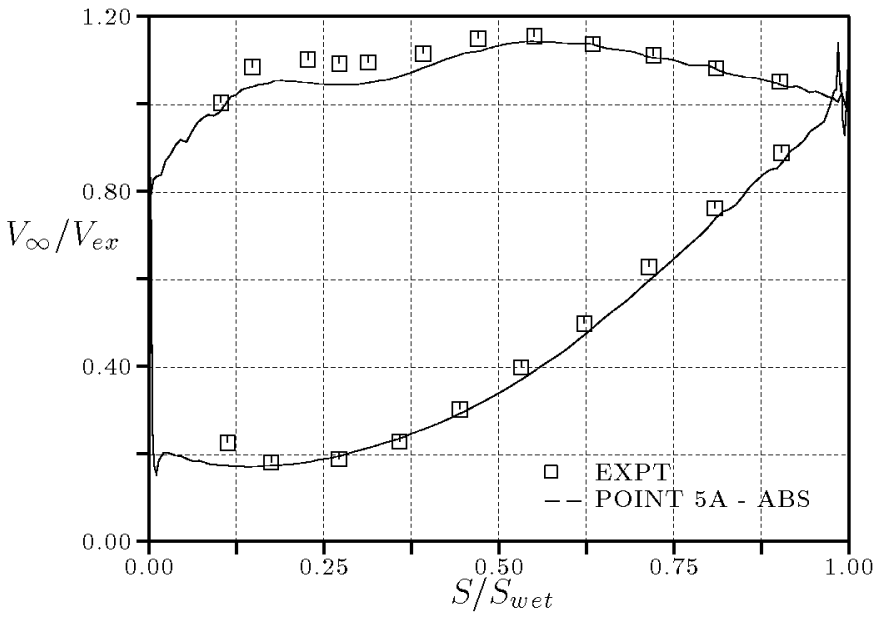

Figure 6: Normalized loading on rotor-2, Point 5A, ABS.

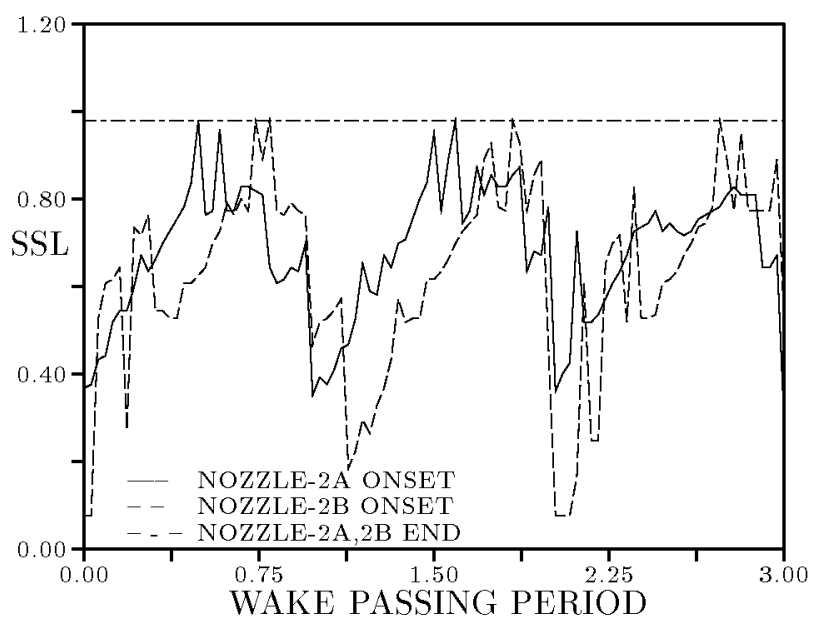




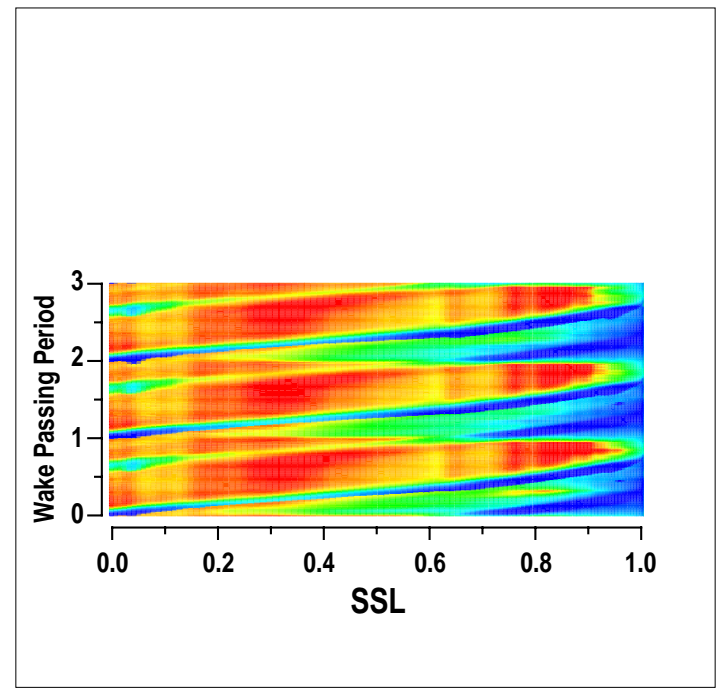

Figure 8: Shape factor from current analysis, Point $5 \mathrm{~A}, \mathrm{ABS}, H_{\min }=1.53, H_{\max }=2.64$.

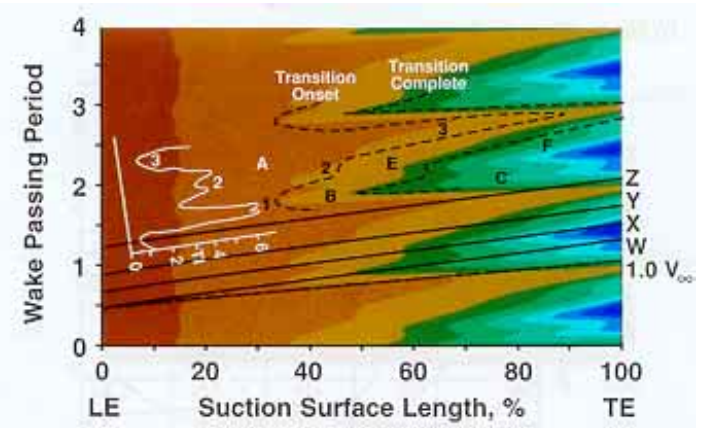

Figure 9: Shape factor from unsteady boundary layer code, Point 5A, ABS, $H_{\min }=1.53, H_{\max }=2.64$.
Figure 10: Displacement thickness, nozzle-2, Point $5 \mathrm{~A}, 50 \%$ SSL.

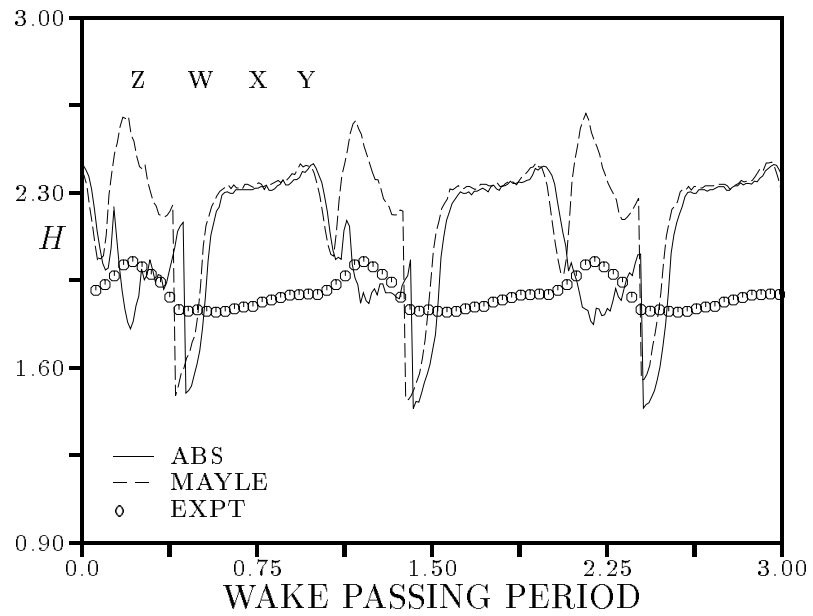

Figure 11: Shape factor, nozzle-2, Point 5A, 50\% SSL.

WAKE PASSING PERIOD

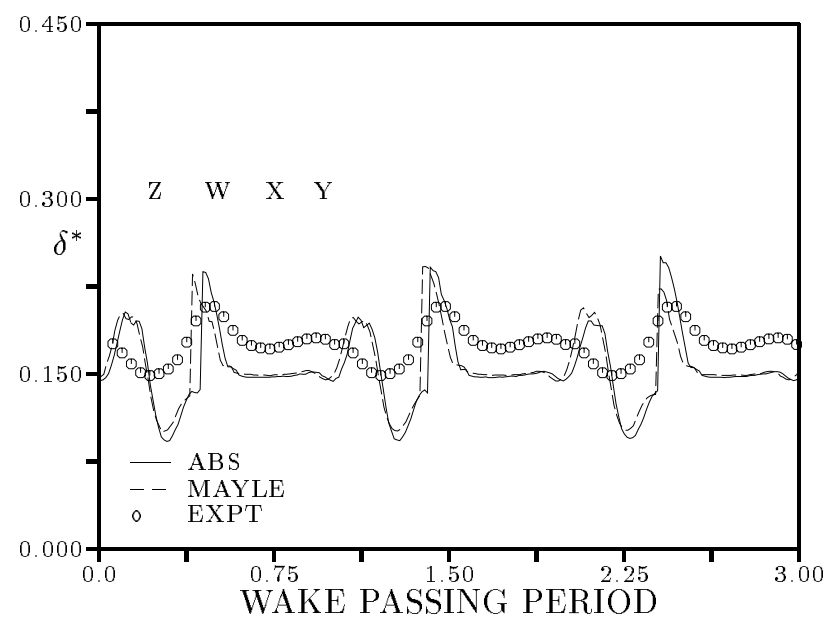




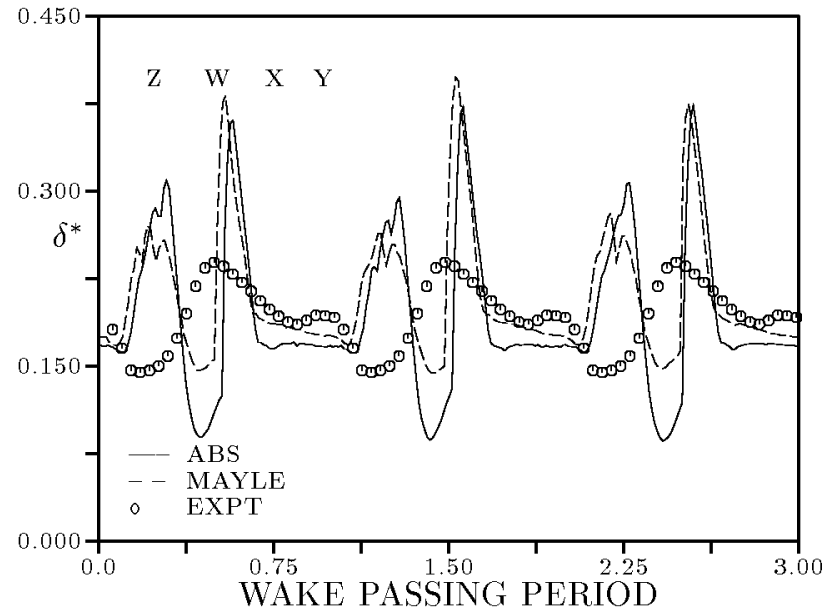

Figure 12: Displacement thickness, nozzle-2, Point $5 \mathrm{~A}, 68 \%$ SSL.

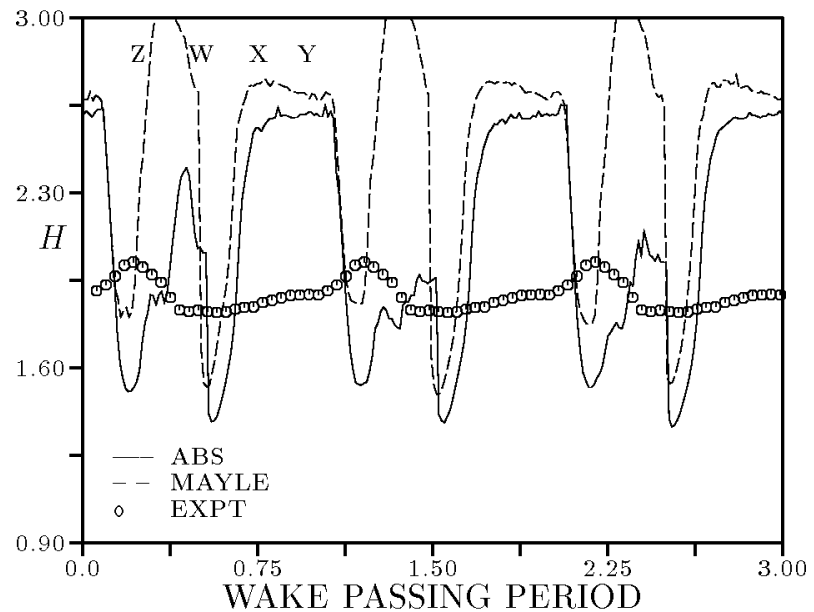

Figure 13: Shape factor, nozzle-2, Point 5A, $68 \%$ SSL.

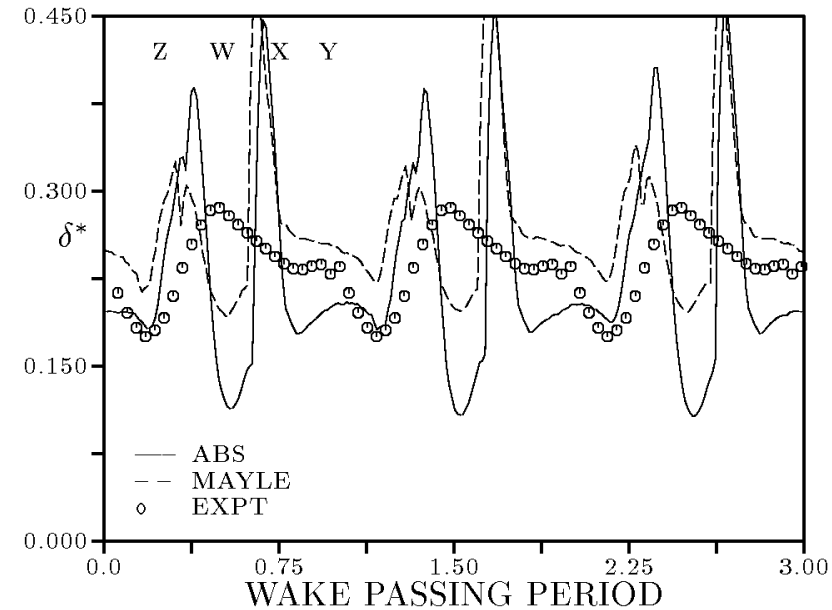

Figure 14: Displacement thickness, nozzle-2, Point $5 \mathrm{~A}, 82 \%$ SSL.

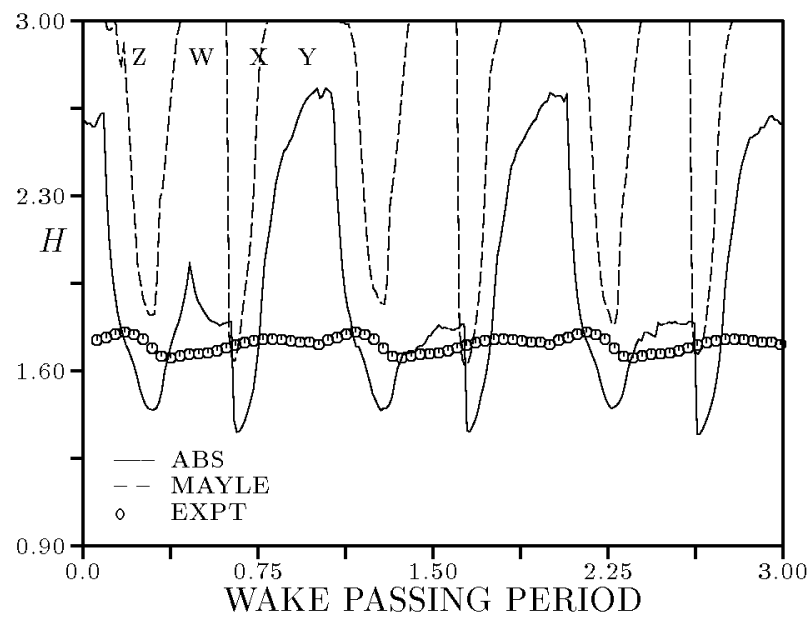

Figure 15: Shape factor, nozzle-2, Point 5A, $82 \%$ SSL. 


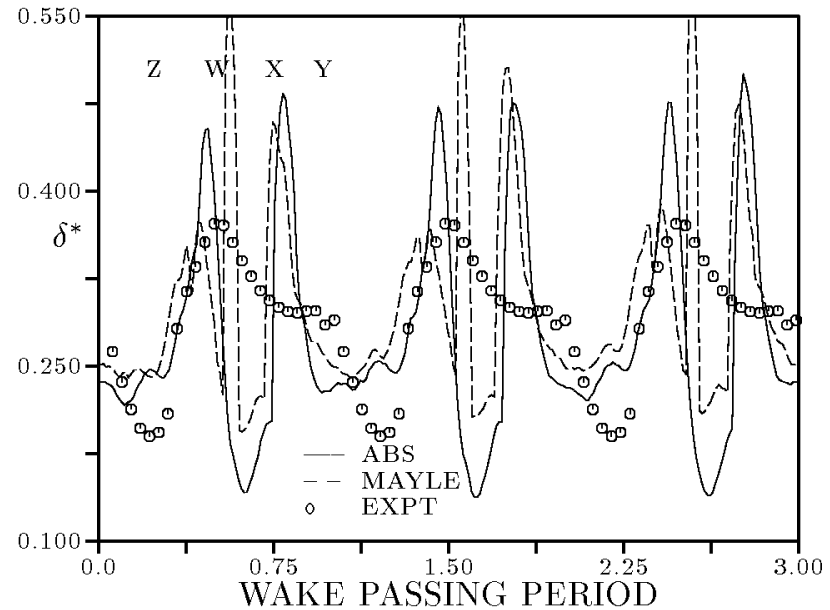

Figure 16: Displacement thickness, nozzle-2, Point $5 \mathrm{~A}, 94 \%$ SSL.

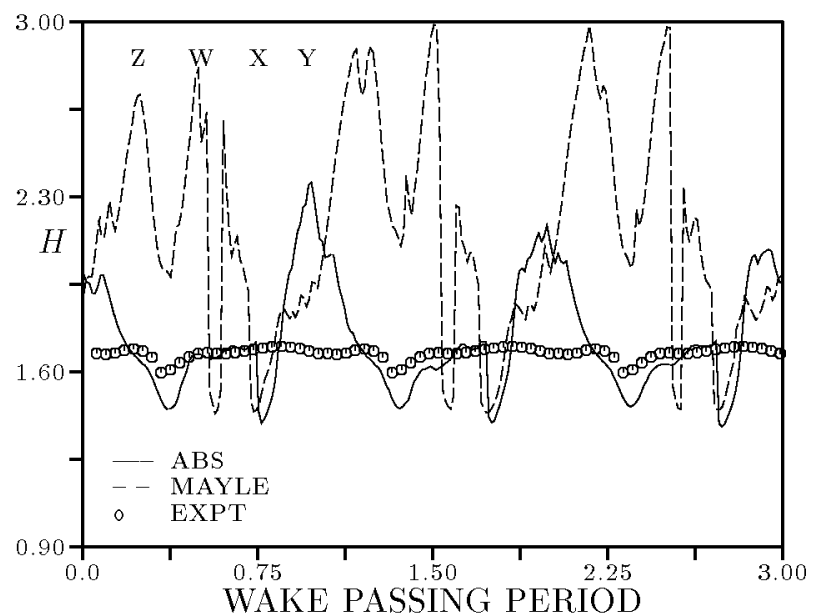

Figure 17: Shape factor, nozzle-2, Point 5A, 94\% SSL.

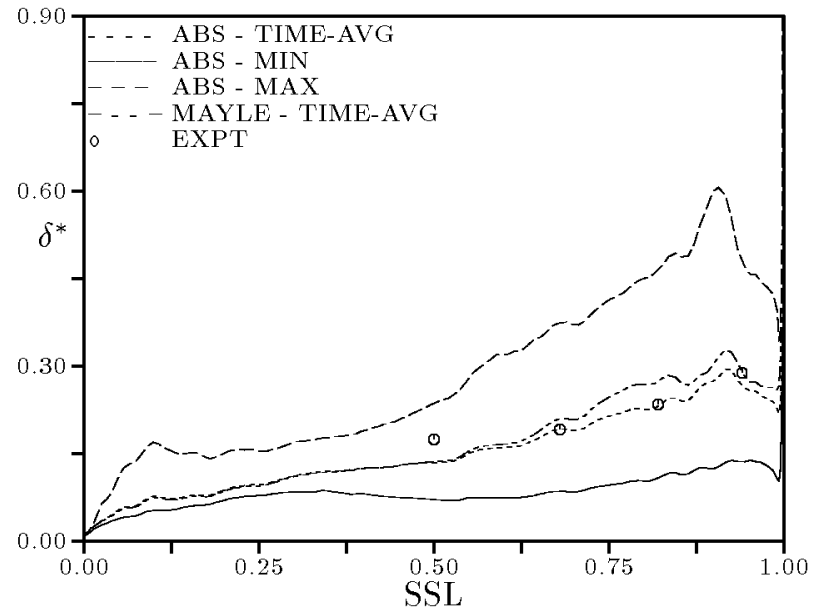

Figure 18: Displacement thickness envelope, nozzle2, Point 5A.

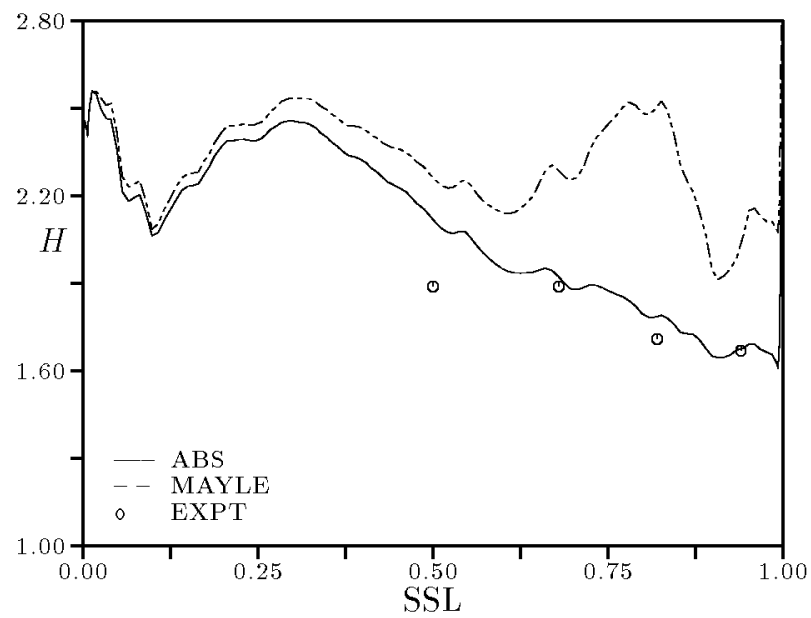

Figure 19: Time-averaged shape factor, nozzle-2, Point 5A. 

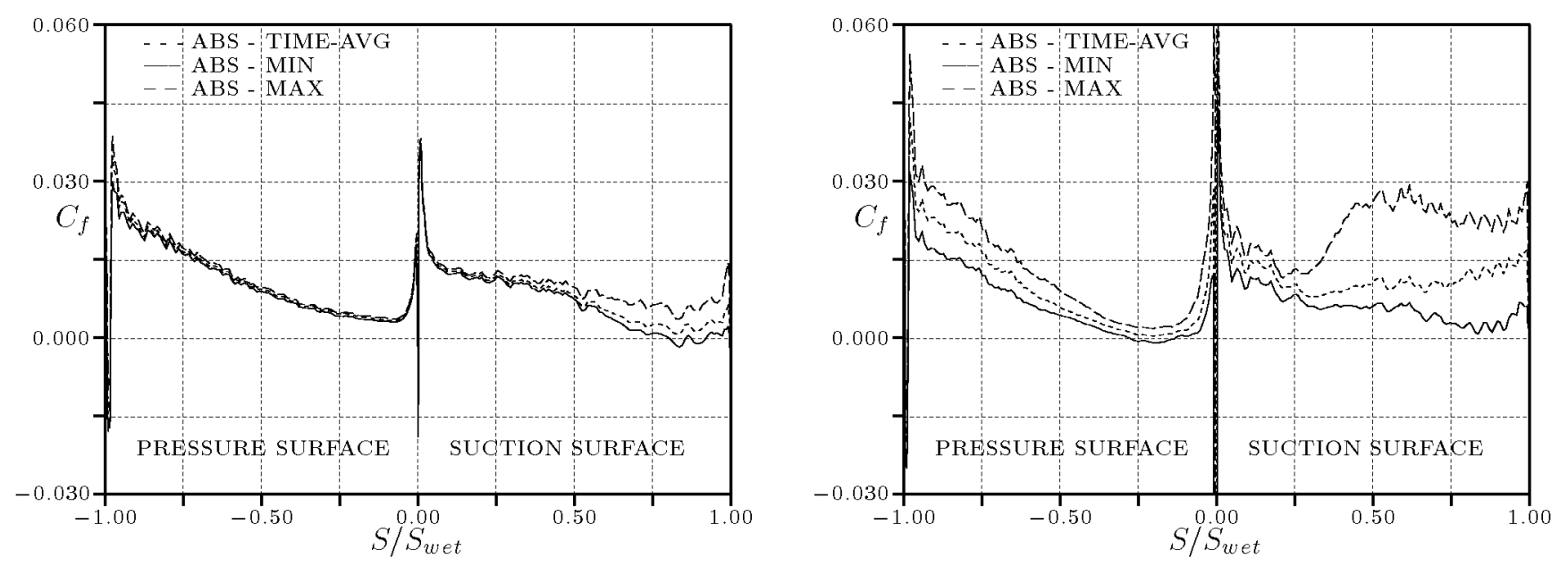

Figure 20: Skin friction envelope, nozzle-1, Point 5A. Figure 22: Skin friction envelope, nozzle-2, Point 5A.
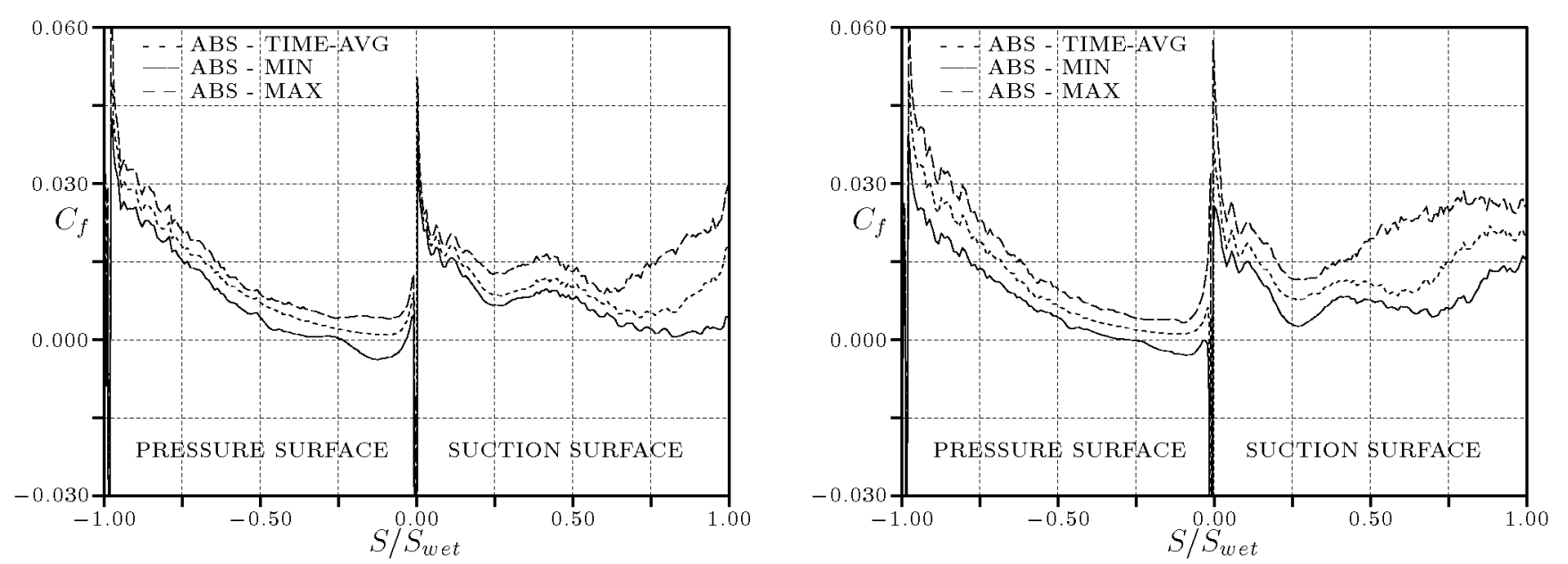

Figure 21: Skin friction envelope, rotor-1, Point 5A.

Figure 23: Skin friction envelope, rotor-2, Point 5A. 


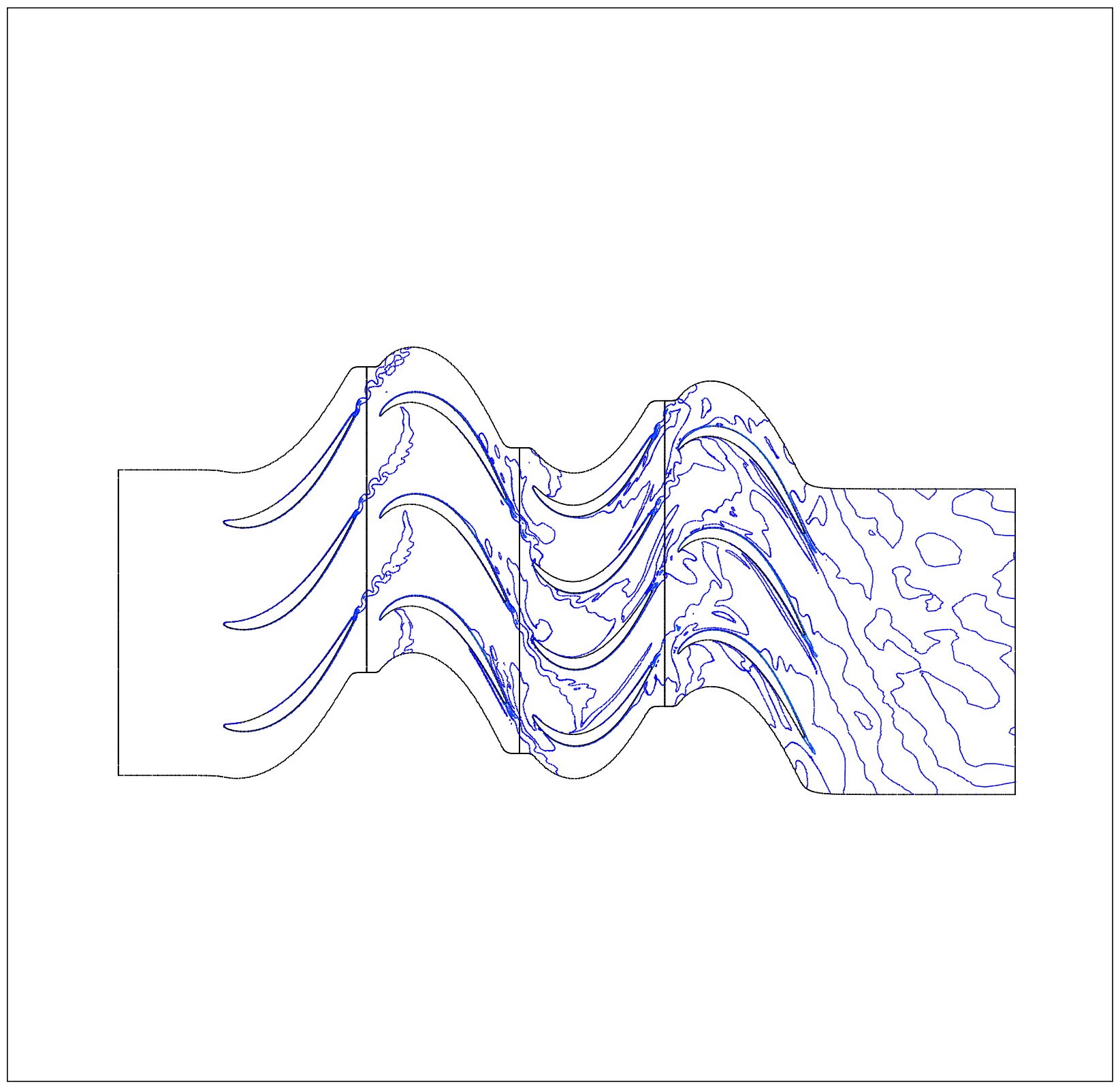

Figure 24: Instantaneous entropy contours, Point 5D, ABS. 


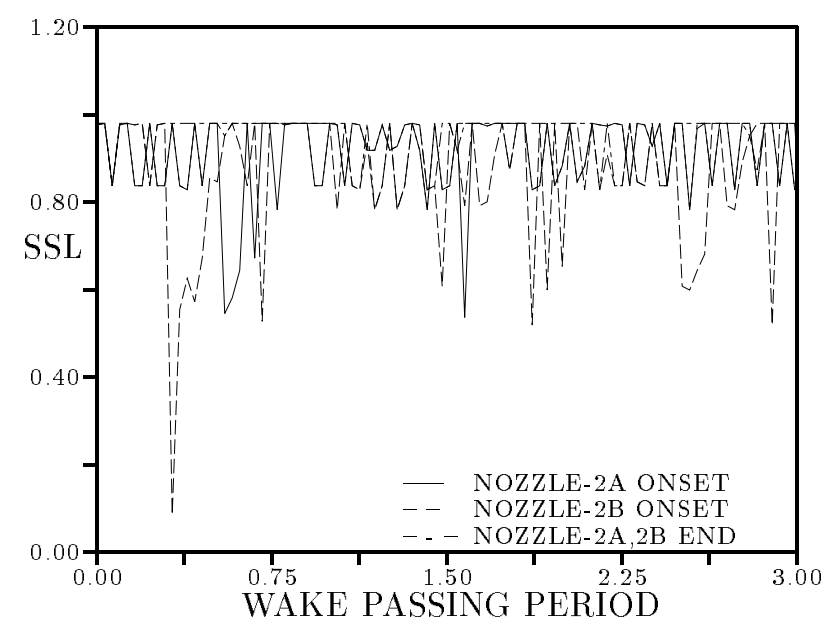

Figure 25: Transition location history, Point 5D, ABS.

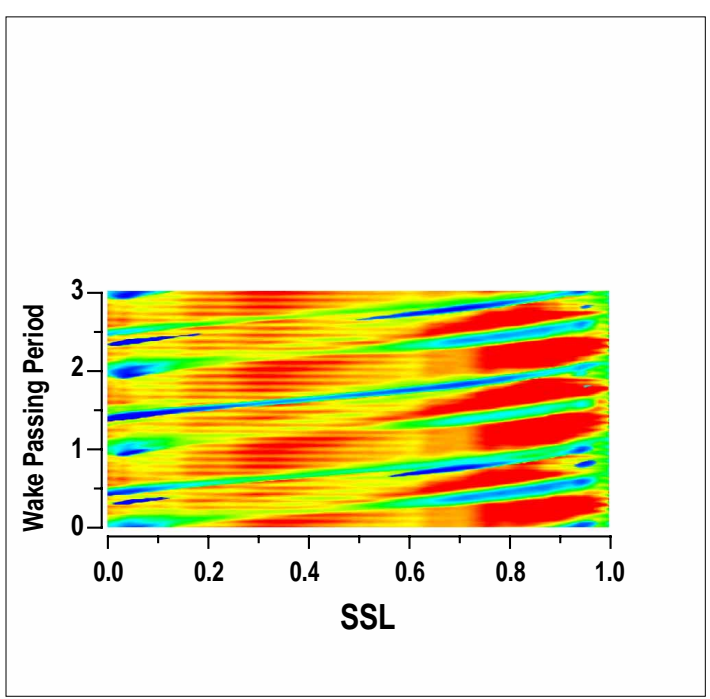

Figure 26: Shape factor from current analysis, Point $5 \mathrm{D}, \mathrm{ABS}, H_{\min }=1.53, H_{\max }=2.64$.

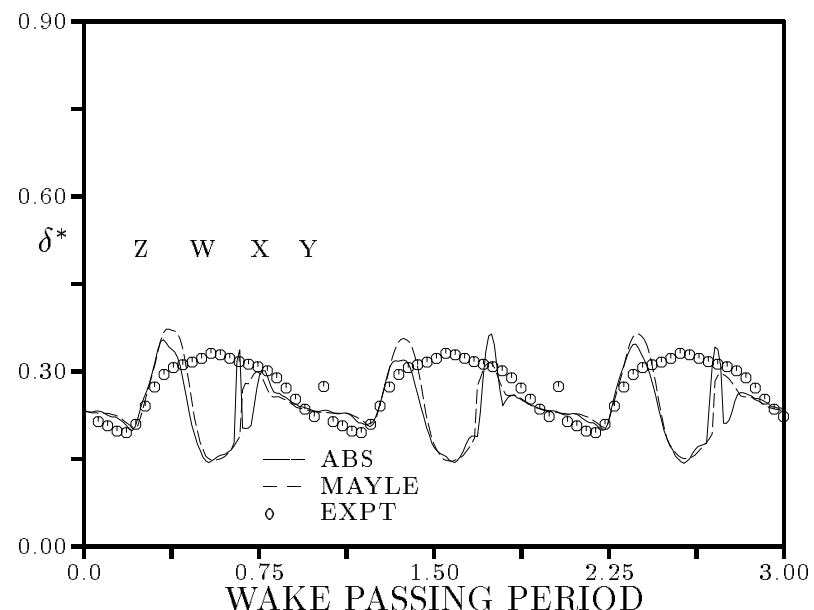

Figure 27: Displacement thickness, nozzle-2, Point 5D, $50 \%$ SSL.

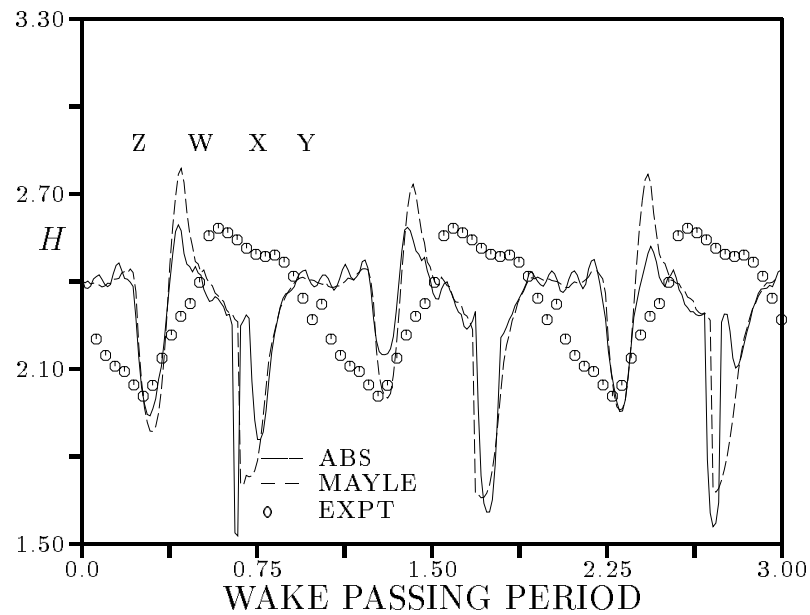

Figure 28: Shape factor, nozzle-2, Point 5D, 50\% SSL. 


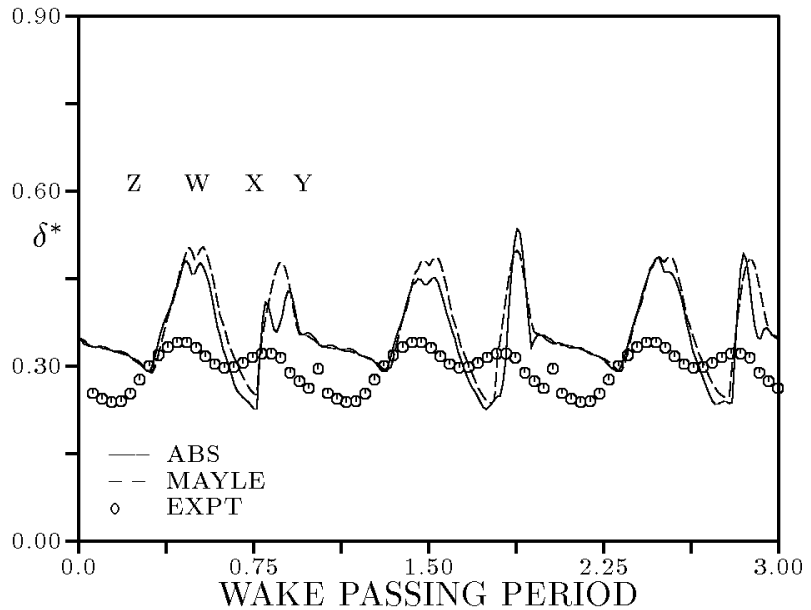

Figure 29: Displacement thickness, nozzle-2, Point $5 \mathrm{D}, 68 \% \mathrm{SSL}$.

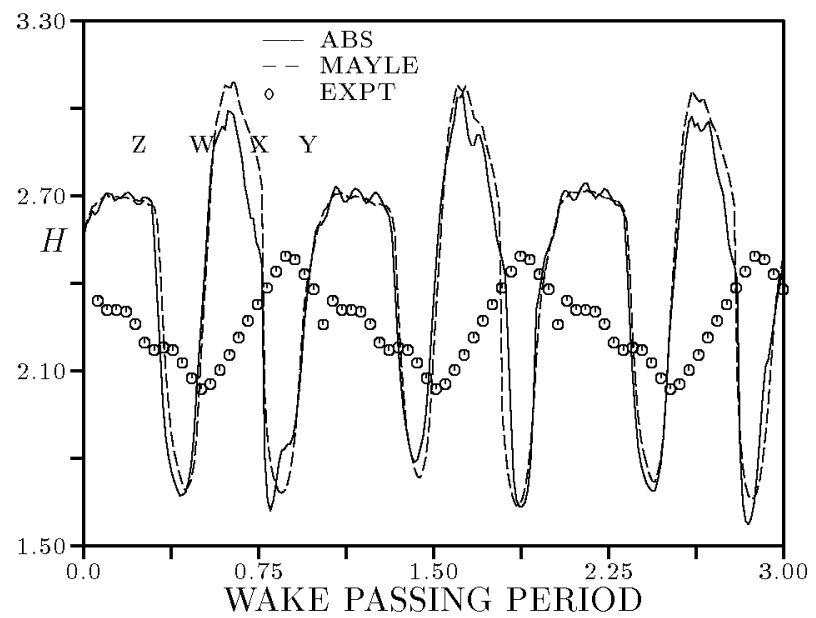

Figure 30: Shape factor, nozzle-2, Point 5D, 68\% SSL.

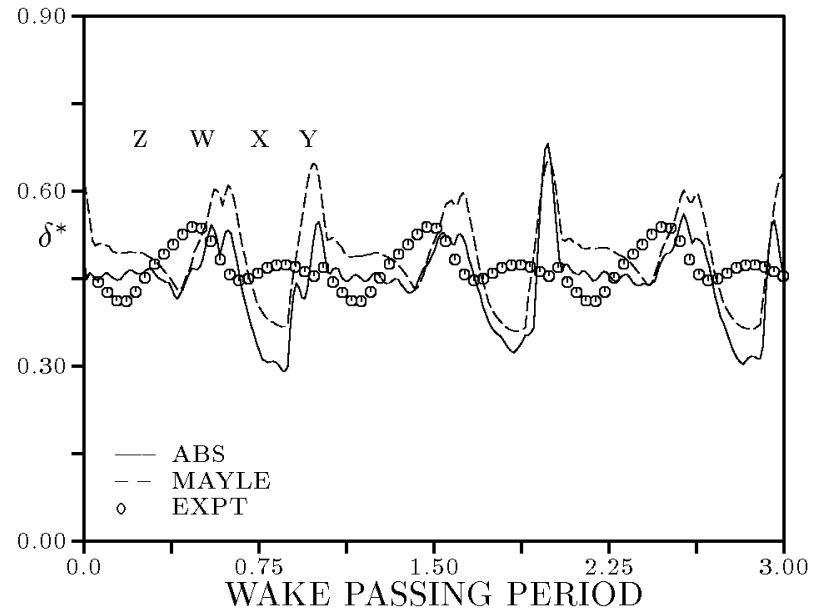

Figure 31: Displacement thickness, nozzle-2, Point 5D, $82 \%$ SSL.

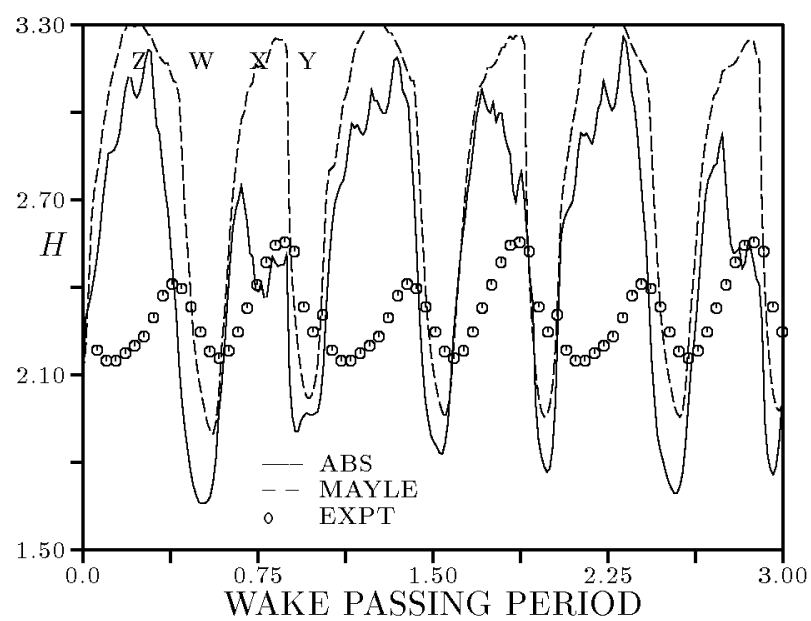

Figure 32: Shape factor, nozzle-2, Point 5D, $82 \%$ SSL. 


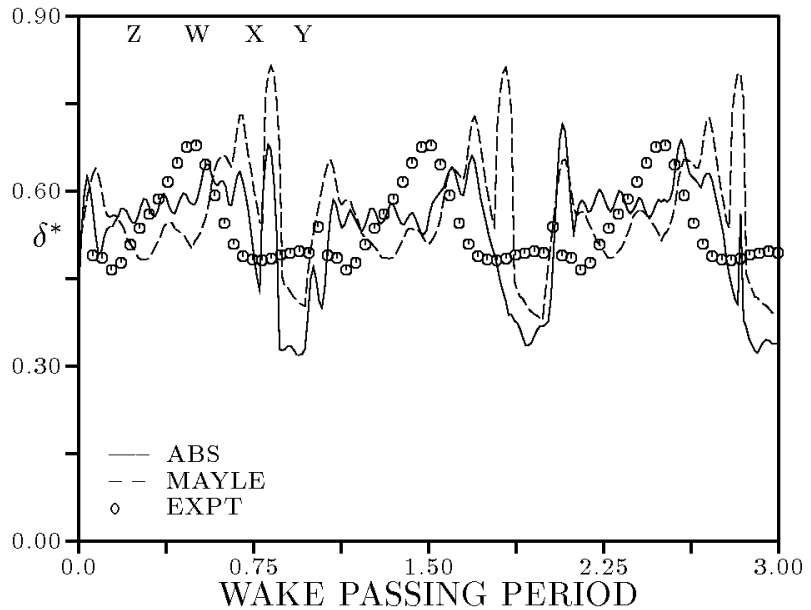

Figure 33: Displacement thickness, nozzle-2, Point 5D, $94 \%$ SSL.

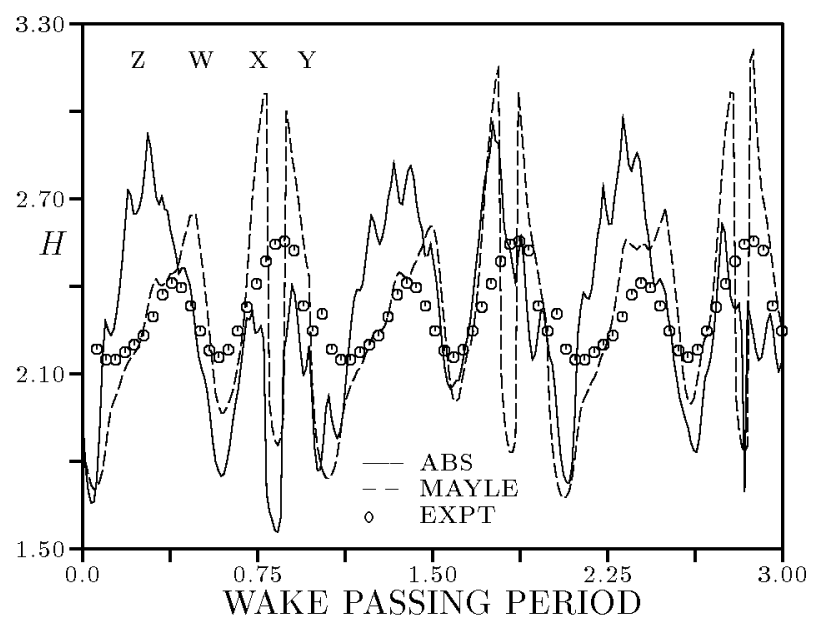

Figure 34: Shape factor, nozzle-2, Point 5D, 94\% SSL.

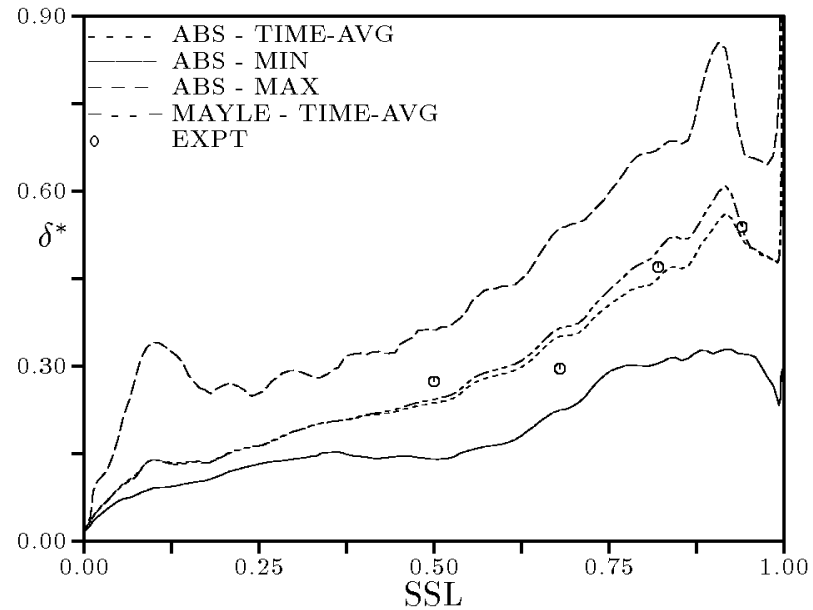

Figure 35: Displacement thickness envelope, nozzle2, Point 5D.

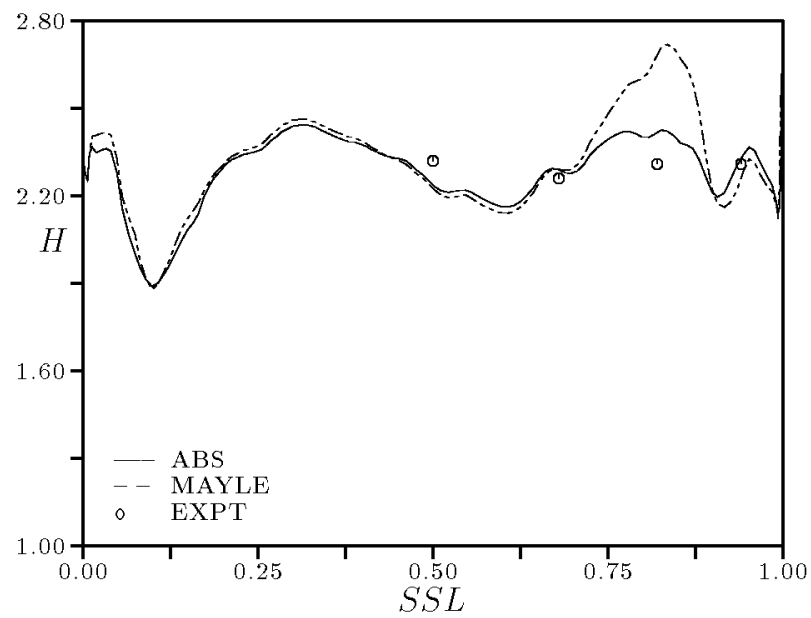

Figure 36: Time-averaged shape factor, nozzle-2, Point 5D. 


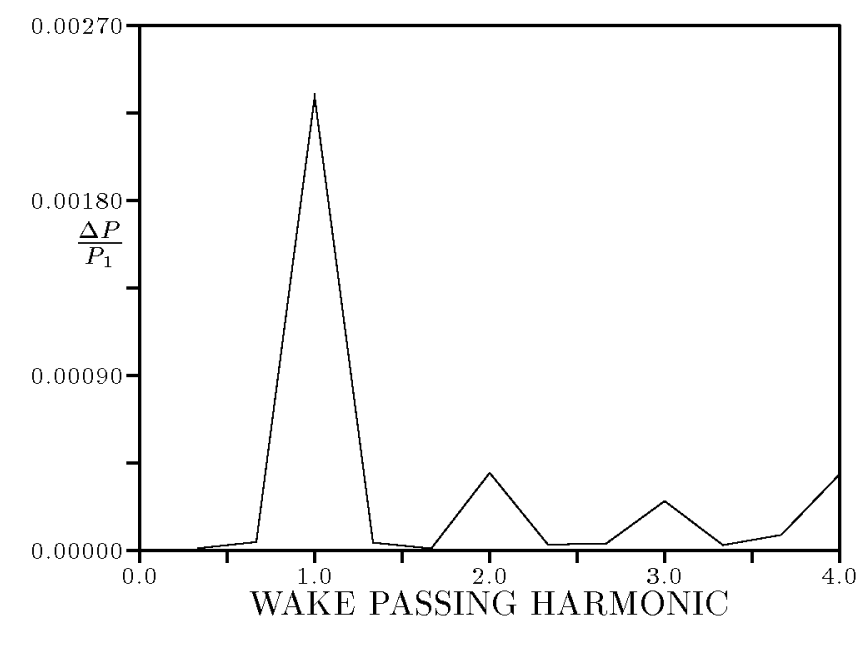

Figure 37: Pressure decomposition, nozzle-2, Point $5 \mathrm{~A}, 96 \%$ SSL.

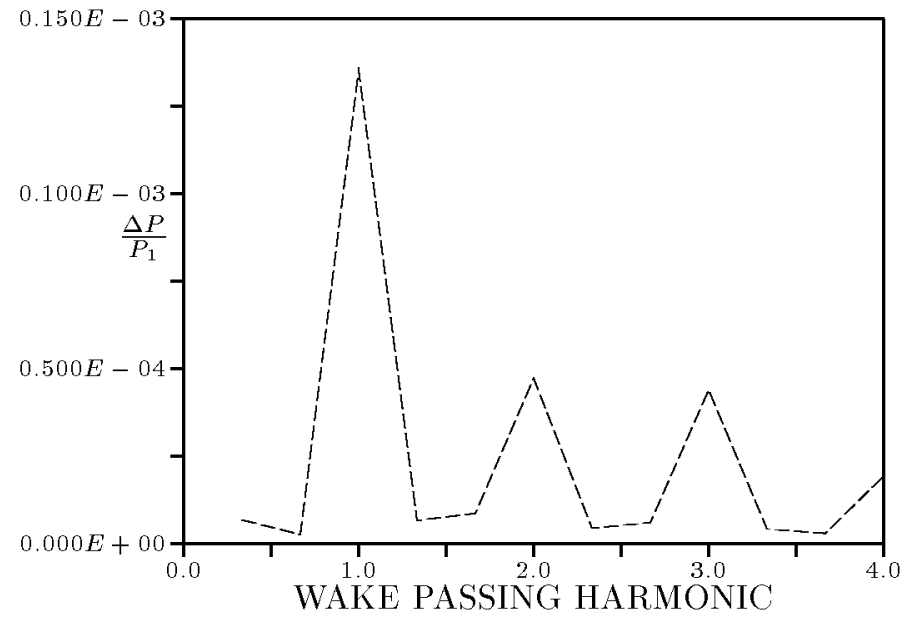

Figure 38: Pressure decomposition, nozzle-2, Point 5D, $96 \%$ SSL.

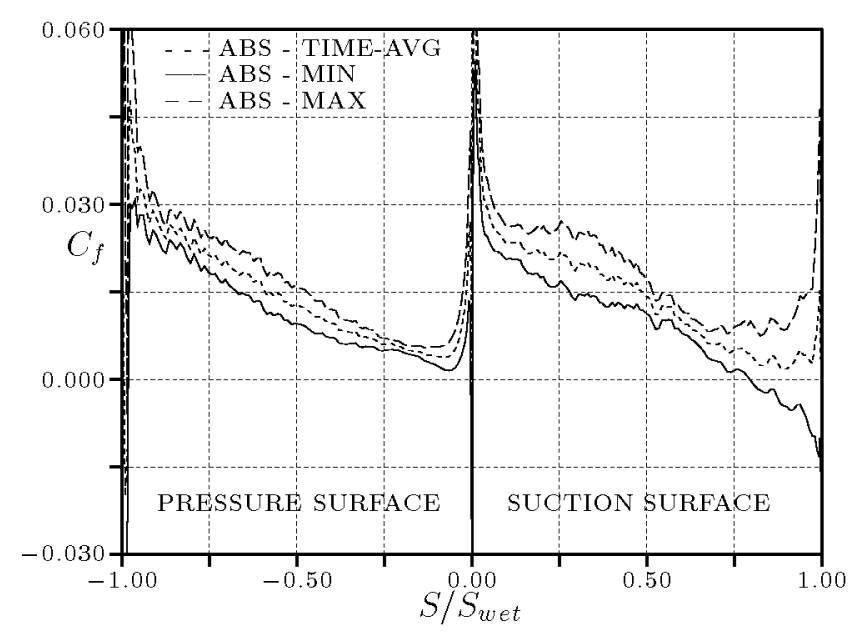

Figure 39: Skin friction envelope, nozzle-1, Point 5D.

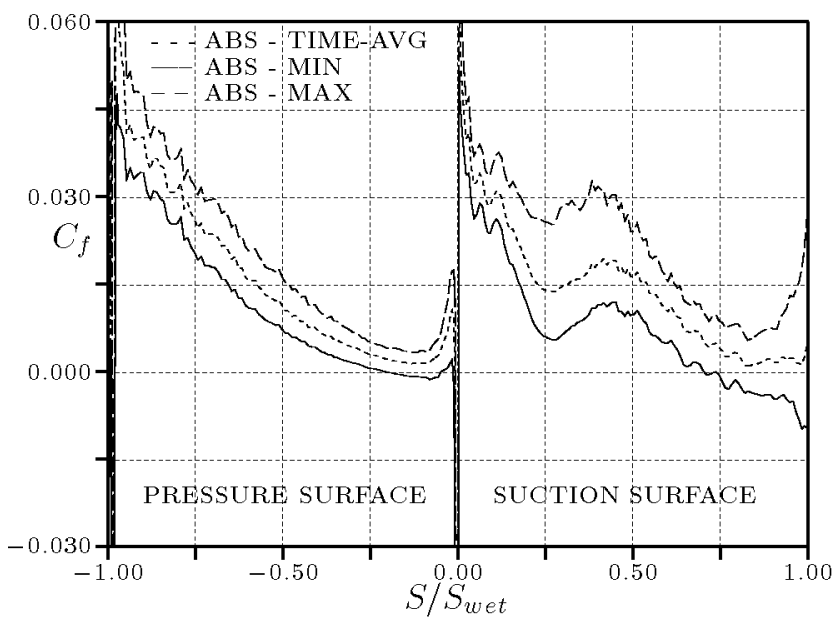

Figure 40: Skin friction envelope, rotor-1, Point 5D. 


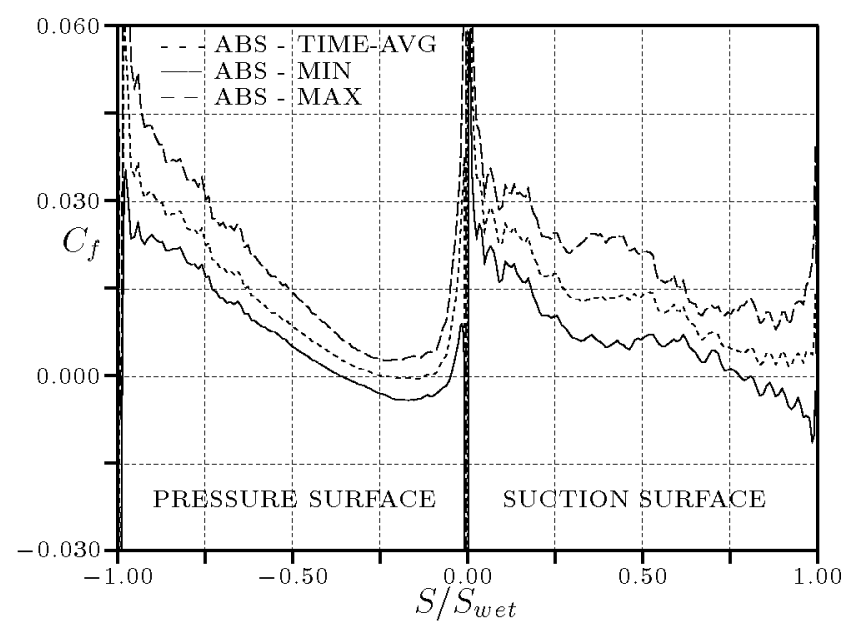

Figure 41: Skin friction envelope, nozzle-2, Point 5D.

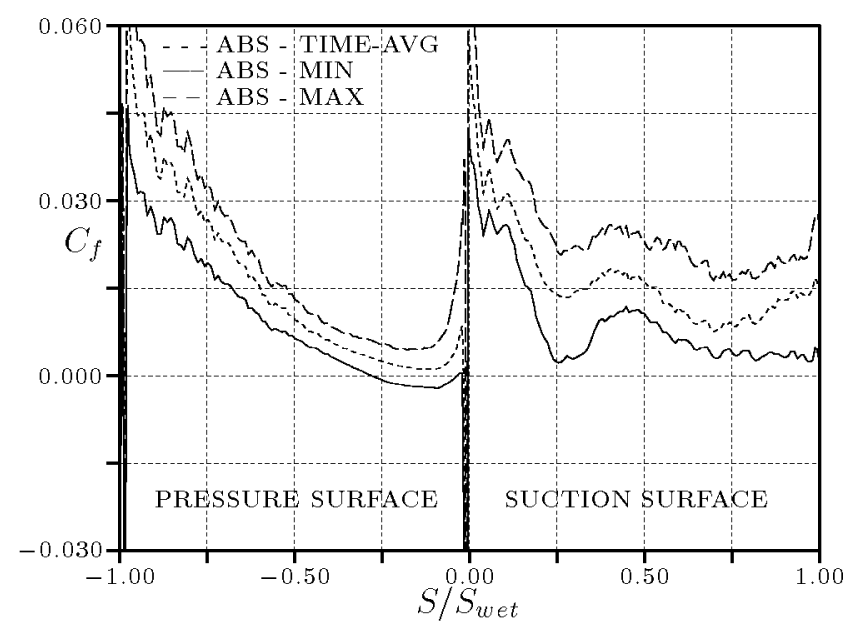

Figure 42: Skin friction envelope, rotor-2, Point 5D. 
\begin{tabular}{|l|c|c|}
\hline 1. AGENCY USE ONLY (Leave blank) & $\begin{array}{c}\text { 2. REPORT DATE } \\
\text { February } 1999\end{array}$ & $\begin{array}{r}\text { 3. REPORT TYPE AND DATES COVERED } \\
\text { Technical Memorandum }\end{array}$ \\
\hline
\end{tabular}

4. TITLE AND SUBTITLE 5. FUNDING NUMBERS

Study of Boundary Layer Development in a Two-Stage Low-Pressure Turbine

6. AUTHOR(S)

WU-523-26-33-00

Daniel J. Dorney, David E. Ashpis, David E. Halstead, and David C. Wisler

7. PERFORMING ORGANIZATION NAME(S) AND ADDRESS(ES)

National Aeronautics and Space Administration

Lewis Research Center

Cleveland, Ohio 44135-3191

8. PERFORMING ORGANIZATION

REPORT NUMBER

E-11544

9. SPONSORING/MONITORING AGENCY NAME(S) AND ADDRESS(ES)

National Aeronautics and Space Administration

Washington, DC 20546-0001

10. SPONSORING/MONITORING

AGENCY REPORT NUMBER

NASA TM-1999-208913

AIAA-99-0742

11. SUPPLEMENTARY NOTES

Prepared for the 37th Aerospace Sciences Meeting \& Exhibit sponsored by the American Institute of Aeronautics and Astronautics, Reno, Nevada, January 11-14, 1999. Daniel J. Dorney, Virginia Commonwealth University, Richmond, Virginia (work funded by NASA Cooperative Agreement NCC3-645); David E. Ashpis, NASA Lewis Research Center; David E. Halstead and David C. Wisler, GE Aircraft Engines, Cincinnati, Ohio. Responsible person, David E. Ashpis, organization code 5820, (216) $433-8317$.

\begin{tabular}{|l|l}
\hline 12a. DISTRIBUTION/AVAILABILITY STATEMENT & 12b. DISTRIBUTION CODE
\end{tabular}

Unclassified - Unlimited

Subject Categories: 02 and $07 \quad$ Distribution: Nonstandard

This publication is available from the NASA Center for AeroSpace Information, (301) 621-0390.

13. ABSTRACT (Maximum 200 words)

Experimental data from jet-engine tests have indicated that unsteady blade row interactions and separation can have a significant impact on the efficiency of low-pressure turbine stages. Measured turbine efficiencies at takeoff can be as much as two points higher than those at cruise conditions. Several recent studies have revealed that Reynolds number effects may contribute to the lower efficiencies at cruise conditions. In the current study numerical simulations have been performed to study the boundary layer development in a two-stage low-pressure turbine, and to evaluate the transition models available for low Reynolds number flows in turbomachinery. The results of the simulations have been compared with experimental data, including airfoil loadings and integral boundary layer quantities. The predicted unsteady results display similar trends to the experimental data, but significantly overestimate the amplitude of the unsteadiness. The time-averaged results show close agreement with the experimental data.

\section{SUBJECT TERMS}

Turbomachinery; Turbines; Transition; Separation; Turbulence; Modeling

\begin{tabular}{|c|c|c|}
\hline $\begin{array}{c}\text { 17. SECURITY CLASSIFICATION } \\
\text { OF REPORT } \\
\text { Unclassified }\end{array}$ & $\begin{array}{c}\text { 18. SECURITY CLASSIFICATION } \\
\text { OF THIS PAGE } \\
\text { Unclassified }\end{array}$ & $\begin{array}{c}\text { 19. SECURITY CLASSIFICATION } \\
\text { OF ABSTRACT } \\
\text { Unclassified }\end{array}$ \\
\hline
\end{tabular}

